\title{
Motor Neuronal Receptive Fields Delimit Patterns of Motor Activity During Locomotion of the Locust
}

\author{
Gilles Laurent ${ }^{1}$ and Reinhold Hustert ${ }^{2}$ \\ ${ }^{1}$ Department of Zoology, University of Cambridge, Cambridge CB2 3EJ, England, and ${ }^{2}$ Fachbereich Biologie, Universitat \\ Konstanz, D-7750 Konstanz, Federal Republic of Germany
}

\begin{abstract}
During walking, the muscles of a leg undergo a typical sequence of activity, which is partly shaped by phasic sensory feedback. To assess the role played by such feedback, we characterized intracellularly the receptive fields of tarsal motor neurons in the locust Schistocerca gregaria and considered these receptive fields within the context of a step cycle.

The depressor motor neurons, active during the stance phase, are excited by ventral tarsal contact or an imposed levation and are inhibited by dorsal contact or an imposed depression. Partial deafferentation of the anterior tarsus reduces this stance phase depressor activity. The levator motor neuron, active during the swing phase, has the opposite receptive field. The retractor unguis motor neurons, synergistic to the depressors, are, like them, excited by ventral contact but, like the levator, are inhibited by afferents which can signal the end of the stance phase. The inhibition of the retractors could constitute a preparation for the swing phase, by reducing the grip on the substrate. The motor neuronal receptive fields thus appear to support the patterns of muscular activity recorded during walking.

Excitation of the motor neurons by extero- and proprioceptors is usually direct: hair, canal, campaniform, and chordotonal afferents all evoke 1:1 EPSPs in motor neurons after a central latency of 1-1.5 msec. Inhibition is indirect, as IPSPs occur at least $2 \mathrm{msec}$ later than the EPSPs. The motor neurons of one pool have overlapping but not necessarily identical, receptive fields. Parallel, supplementary excitatory and inhibitory pathways involving nonspiking local interneurons also exist, which can allow gain control of a specific reflex. The weight given to a reflex response will thus depend, first, on the number of motor neurons in a pool affected by the stimulus and, second, on the existence and state of intercalated interneurons.
\end{abstract}

Phasic sensory feedback plays a crucial role in shaping and stabilizing locomotor output. Deafferented preparations can express bouts of rhythmic activity that resemble locomotor patterns (von Holst, 1935; Wilson, 1961; Delcomyn, 1980; Jordan, 1983; Grillner, 1985; Stevenson and Kutsch, 1987), but such

\footnotetext{
Received Jan. 29, 1988; revised Mar. 25, 1988; accepted Mar. 25, 1988

We are grateful to Peter Bräunig, Malcolm Burrows, Debby Kuterbach, Kay Seymour, Dave Shepherd, and Alan Watson for their numerous helpful comments on the manuscript, and to Maggy Bray for her kind help with the scanning electron microscopy. This work was supported by an SERC (UK) grant to M. Burrows and by Grant Hu-223 from the DFG (FRG) to R.H. G.L. is a Locke Research Fellow of the Royal Society.

Correspondence should be addressed to Gilles Laurent at the above address.
}

Copyright (C) 1988 Society for Neuroscience $0270-6474 / 88 / 114349-18 \$ 02.00 / 0$ movements cannot be adjusted to extraneous disturbances or to the constraints of the terrain (Grillner and Zangger, 1984; Giuliani and Smith, 1987). The importance of phasic feedback has, for example, been shown in the locust flight, where the output of the central oscillator is strongly modified and its timing entrained by wing proprioceptive afference to flight motor and interneurons (Pearson et al., 1983; Reye and Pearson, 1987, 1988). Sensory input from the limbs can also modify the basic motor output of a pattern-generating circuit to produce several "behaviors," such as walking and hatching in the chick (Bekoff et al., 1987). Understanding the neural basis of locomotion thus requires a description of the neuronal networks through which these interactions between central and peripheral inputs can occur.

The foot is a major source of phasic inputs during walking, for it both supports and propels the body during the stance phase of a step. It is, by its position, well suited to provide periodic information on contact-thus helping the timing of the step in the homonymous or adjacent limbs-and on load-thus supplementing inputs from the more proximal parts of the leg (Pearson and Duysens, 1976; Loeb, 1985; Zill, 1985). Its functional importance is suggested by the generally high density of mechanoreceptors present at its surface (cat: Stilwell, 1957; Lynn, 1969; Crustacea: Bush and Laverack, 1982; insects: Kendall, 1970). In the cat and the rat, such cutaneous afferents from the foot evoke short-latency postsynaptic potentials in dorsal horn interneurons of the lumbar spinal cord, thereby forming precise receptive fields (Egger et al., 1986; Woolf and Fitzgerald, 1983, 1986; Woolf and King, 1987). The function of these spinal interneurons is so far unknown, but some could be part of the plantar cushion reflex circuit (Engberg, 1964; Egger et al., 1986). In Crustacea, force-sensitive mechanoreceptors of the dactyl lead to reflex adaptation of intra- and interleg patterns of coordination, but the pathways mediating these effects are unknown (Libersat et al., 1987). In the locust, there are some 1300 mechanoreceptor neurons on the surface of a tarsus (Kendall, 1970). Their position is mapped centrally, in the receptive fields of local and intersegmental interneurons with motor outputs (Burrows and Siegler, 1984; Burrows and Watkins, 1986; Laurent, 1987b; Laurent and Burrows, 1988).

Our objective here was thus to study the role of the tarsal mechanoreceptors in shaping the patterns of leg muscle activity of the locust during walking. We followed specific mechanoreceptive signals from the sensory neurons to the leg motor neurons using intracellular recording and evaluated the contribution of the receptive fields so defined to the electromyographic patterns recorded during free locomotion of intact and partially deafferented animals. These experiments, restricted to the 3 

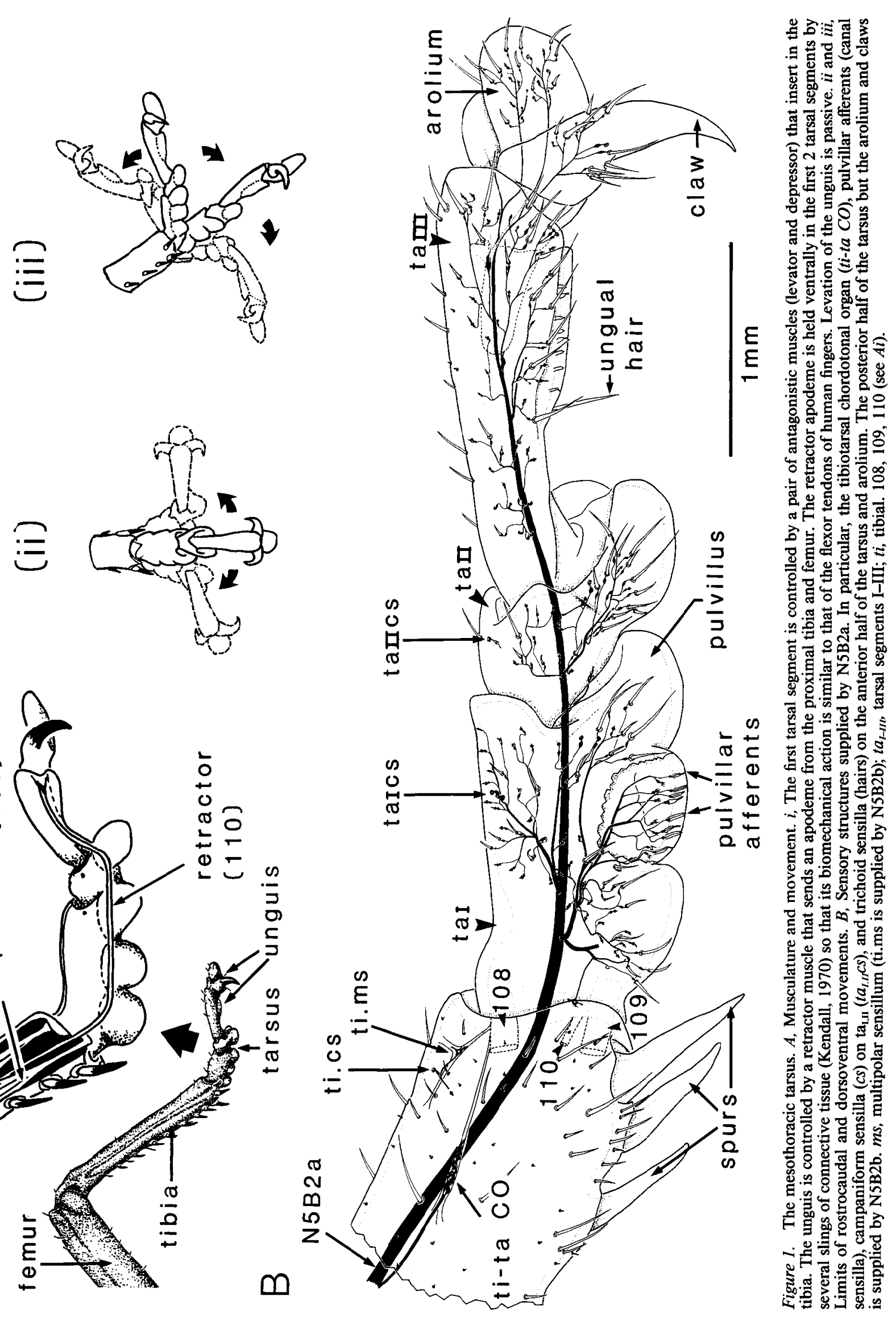
pools of motor neurons controlling the homonymous tarsus, show that the receptive fields of the motor neurons delimit the observed patterns of myographic activity during walking and that the motor responses are well suited to provide the grip necessary to progression during the stance phase of a step.

\section{Materials and Methods}

Adult locusts, Schistocerca gregaria (Forskal), of either sex were used from our laboratory colony. The tarsus is supplied by 4 tibial nerves (Pflüger, 1981). N5B2a3 is purely motor and innervates levator, depressor, and distal retractor muscles. N5B2-a, $-\mathrm{a} 2$, and $-\mathrm{b}$ are purely sensory. N5B2b supplies sense organs on the posterior half of the distal tibia and tarsal segments I-III; N5B2a2, the anterior half of the distal tibia; and N5B2a, the anterior half of ta I-III and the entire pretarsus (Fig. 1B).

Scanning electron microscopy. To identify external mechanoreceptors, tarsi were fixed in $6 \%$ formaldehyde, dehydrated in ethanol/acetone, critical-point-dried, gold-coated, and examined in a Philips SEM 505 scanning electron microscope.

Light microscopy. Internal sense organs were identified by dissection, peripheral axonal filling with cobalt, and physiological characterization. Nomenclature is based on the descriptions of Bräunig et al. (1981), Hustert et al. (1981), and Pflüger et al. (1981), as well as anatomical studies on tarsál sense organs in this and other insects (Usherwood et al., 1968; Kendall, 1970; Young, 1970; Brousse-Gaury, 1981). The central projections of individual afferents were revealed by backfilling them from their dendrites, using $\mathrm{CoCl}_{2}$ and hexammine cobaltic chloride at concentrations between 0.5 and $5 \%$.

Electromyographic $(E M G)$ recording. EMG activity was recorded from the tarsal muscles using 2 or 3 pairs of extracellular electrodes $(30 \mu \mathrm{m}$ steel wire insulated but for the tip) inserted through the cuticle and fixed with wax. The animals were free to walk in a $30 \mathrm{~cm}$ diameter flat arena or to climb up wooden rods. Partial deafferentation (5 animals) was performed after the animals had been cold-anesthetized by sectioning N5B2a through a small window opened in the middorsal tibia. Observation of the animals during walking was done either by eye, while describing the step cycle in the voice channel of the tape recorder, or by using a Philips high-resolution video system. Observation of the distal spurs during walking was done with the video system.

Electrophysiology. The animals were mounted in Plasticine, ventral side up, with all tibiae but the mesothoracic free to move. The mesoand metathoracic ganglia were exposed and stabilized on a wax-coated platform. The thoracic cavity was perfused with fresh saline throughout the experiments. The sheath of the mesothoracic ganglion was treated with a $1 \%(\mathrm{wt} / \mathrm{vol})$ solution of protease (Sigma type XIV) in saline. Extracellular recordings were made from 4 tibial nerves using pairs of extracellular hook electrodes isolated from the saline with petroleum jelly. Individual exteroceptors were stimulated under the binocular with a fine minuten pin mounted on a piezoelectric crystal, driven by a function generator. Individual hairs and spurs could be moved laterally, and campaniform sensilla or canal organs focally deformed by light pressure. It is assumed that canal sensilla subserve mechanoreceptive functions for, like campaniform sensilla, they are supplied by single neurons. Bristles, however, are innervated by 6 neurons, suggesting a chemoreceptive function (Kendall, 1970). Mechanosensitivity from 1 of these 6 neurons is nevertheless possible (Brousse-Gaury, 1981). Proprioceptors were stimulated by imposing movements to their joints using a servomotor driven by a function generator. Individual chordotonal afferents were stimulated electrically by intracellular injection of current in their soma (see below).

Intracellular recordings. Recordings were made from the somata of the mesothoracic tarsal motor neurons and the neuropilar processes of nonspiking local interneurons. Glass micropipettes were filled with $2 \mathrm{M}$ potassium acctatc or a $6 \%$ solution of hexammine cobaltic chloride (Brogan and Pitman, 1981) for later staining. Only one neuron could be stained in each experiment. The neurons were identified by intracellular injection of current and observation of the evoked tarsal movements and of the motor spikes in nerve $5 \mathrm{~B} 2 \mathrm{a}_{3}$. Intracellular recordings were also made from individual sensory afferents in the tibiotarsal chordotonal organ. Their cell bodies were impaled in the periphery with a glass micropipette filled with $2 \mathrm{~m}$ potassium acetate, while the organ was supported by a small wax-coated platform. Recordings were stored on a 7-channel Racal FM tape recorder for later averaging, display on a Gould ES1000 printer, or on a Nicolet or Gould digital oscilloscope and Philips X-Y plotter. These physiological results are based on experiments in 47 animals and comprise 81 intracellular recordings from tarsal motor neurons and 39 from nonspiking local interneurons.

The central latencies to PSPs evoked by stimulation of individual sensory receptors were calculated as follows: the conduction velocity of a sensory afferent spike was measured between a recording site on a tibial nerve and another on N5 in the coxa or the thoracic cavity. The central latency could then be estimated by subtracting the calculated time necessary for spike propagation from the peripheral recording site to the ganglion, from the measured overall delay to the PSP. This central latency thus includes the time taken by the afferent spike to reach the synaptic sites from the entrance of the nerve plus that taken for synaptic transmission.

For intracellular staining, cobalt was iontophoretically injected using square pulses of positive current $(5-10 \mathrm{nA})$ of $0.5 \mathrm{sec}$ at $1 \mathrm{~Hz}$ for 10 $\mathrm{min}$. The neurons were revealed in ammonium sulfide, subsequently intensified with silver (Pitman et al., 1972; Bacon and Altman, 1977), and drawn as whole mounts with a drawing tube attached to a compound microscope. Selected ganglia were embedded in paraffin wax and sectioned transversely $(10-15 \mu \mathrm{m})$. The names of tracts and neuropilar areas are according to Tyrer and Gregory (1982).

\section{Results}

Tarsal myographic activity during locomotion

The partition of the tarsus into 3 subsegments (ta I-III) and a pretarsus (arolium and claws) makes it very mobile (Fig. $1 A$ ). These subsegments are linked by soft cuticle without the condyli found in true joints, so that rostrocaudal movements are also possible (Fig. 1Aii). Active movements of the tarsus, however, only occur in the vertical plane (Fig. 1Aiii), under the action of 3 tibiotarsal (levator, depressor tarsi; distal retractor unguis) and one femorotarsal (proximal retractor unguis) muscle (Fig. 1, $A i$, $B$ ). During walking, depressor and retractor muscles are active simultaneously during the stance phase and silent during the swing phase (Fig. $2 A$ ). The levator muscle is, by contrast, mainly active during the swing phase and inhibited at the beginning of the stance phase (Fig. $2 A$ ). To assess the contribution of tarsal sensory feedback to this pattern of activity, the tarsus was partially deafferented (Fig. $2 B$ ). Cutting N5B2a, supplying receptors on the anterior half of the tarsus, substantially reduced the tonic depressor activity in the second half of the stance phase (Fig. $2 B$ ). Also, in an intact animal, touching the anterior dorsal surface of the tarsus during the swing phase (Fig. $2 C$ arrows) often disrupted the on-going locomotor activity. It reliably evoked a withdrawal of the leg and a tarsal levation (Fig. $2 C$ dots), suggestive of a compensatory response functionally similar to the "stumbling corrective reaction" observed in cats (Forssberg, 1979).

\section{Contact sensitivity}

Tarsal motor neurons were revealed in the mesothoracic ganglion by backfilling them from their respective nerve branches or individual muscle in the periphery. A backfill of nerve $5 \mathrm{~B} 2 \mathrm{a}_{3}$, the motor nerve supplying all tibiotarsal muscles, and of that to the proximal retractor unguis muscle in the femur revealed a maximum of 12 motor neurons (Fig. $3 \mathrm{~A}$ ): 1 levator tarsi, 5 depressor tarsi, and 6 retractor unguis ( 3 distal and 3 proximal). It is, however, possible that not all the motor neurons were revealed by this method. Most of these motor neurons were then identified as individuals by intracellular staining (e.g., Fig. $3 B-F)$, and physiological characterization as fast, slow, or intermediate, depending on their tonic activity at rest, their threshold for activation by intracellular injection of current, and the dynamic properties of the movements they evoked. 
Figure 2. Tarsal electromyographic (EMG) activity during walking. $A$, Simultaneous EMGs from the 3 tarsal muscles during free walking on a horizontal surface (intact preparation). The levator muscle is controlled by a single unit, active mainly during the swing phase. Retractor and depressor muscles contain several units, active synchronously during the stance phase. $B$, Effect of partial deafferentation. EMG activity recorded before $(i)$ and after (ii) section of N5B2a, which contains sensory axons from the anterior half of the tarsus (Fig. 1B). Deafferentation reduces the tonic depressor activity at the end of the stance phase. $C$, Disruption of the step cycle. Touching the dorsal surface of the tarsus during the swing phase (arrows) can interrupt the step cycle and evoke levator activity (dots), accompanied by a withdrawal of the leg. Records in $A-C$ are from 3 different animals, and in all cases, retractor activity was recorded from the femoral (proximal) bundle.
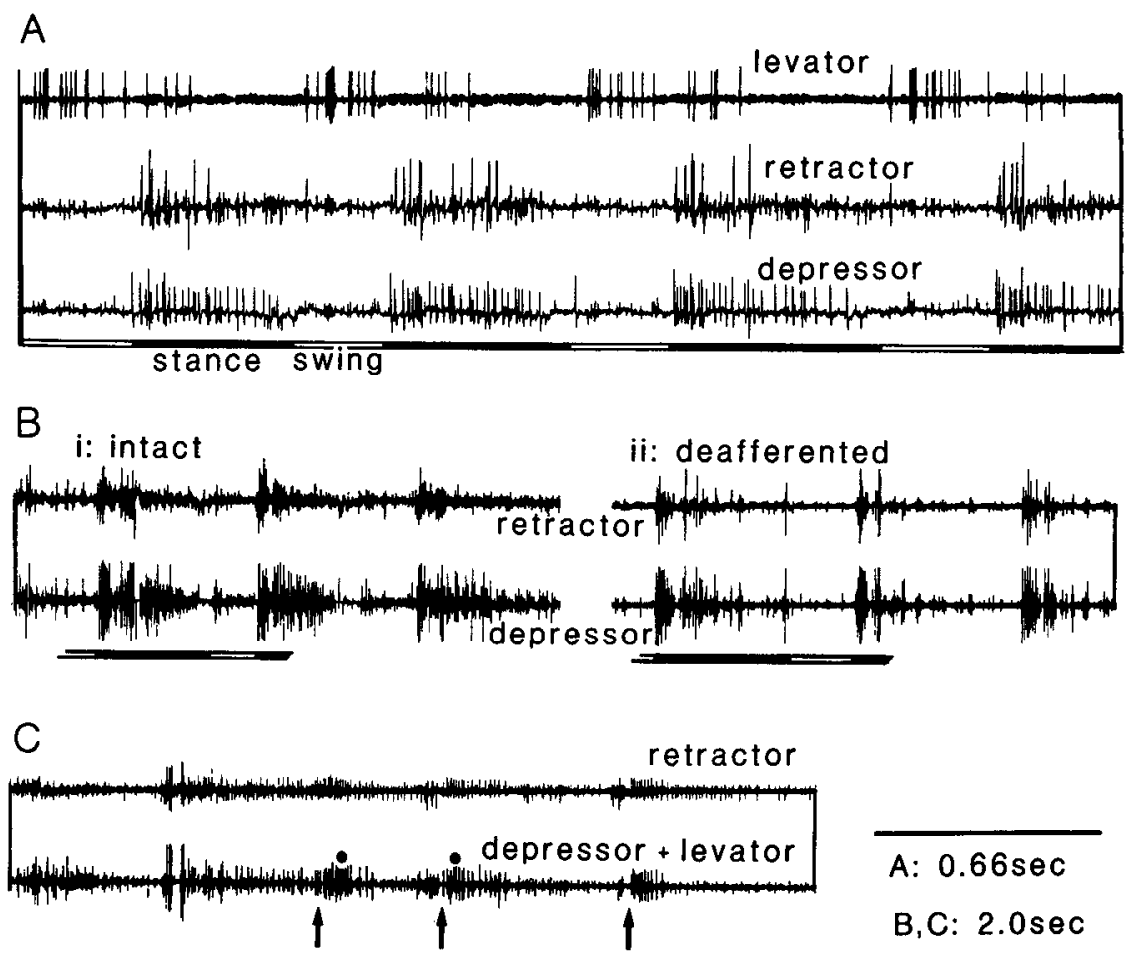

A: $0.66 \mathrm{sec}$

$B, C: 2.0 \mathrm{sec}$

\section{Pulvilli (canal sensilla)}

Tarsal contact with the ground at the start of the stance phase is signaled by the receptors on the pulvilli, soft pads devoid of hairs on the ventral surface of ta I-II (Figs. 1, 4A). These receptors consist of (1) "canal sensilla" (Fig. 4B), each innervated by a single large sensory neuron (Fig. $4 D$ ) and which respond, like campaniform sensilla, to cuticular deformation; and (2) short and multiply innervated bristles or basiconic sensilla (Fig. $4 C$ ), which probably have a chemoreceptive function.

A light pressure applied to the first posterior pulvillus evokes bursts of canal afferent spikes and large depolarizations simultaneously in a depressor and a retractor motor neuron (Fig. 5A). Stimulation of a single afferent can evoke a depolarization in a depressor (Fig. 5B) or a retractor (Fig. 5C) motor neuron. Each afferent spike evokes a depolarizing potential after a constant central latency of about $1.5 \mathrm{msec}$ (here with a retractor motor neuron: Fig. 5, $E, F$ ). These potentials increase in amplitude if steady hyperpolarizing current is applied to the motor neuron and can summate to evoke spikes, indicating that they are EPSPs. These findings indicate that the connections between the afferents and motor neurons are direct, but the presence of an intercalated nonspiking local interneuron cannot be ruled out entirely. We did not find any homosynaptic facilitation (e.g., Fig. $5 E)$.

Although mostly parallel, the effects of the pulvillar canal afferent spikes were sometimes limited to 1 of the 2 classes of motor neurons (Fig. 5A, arrow). Paired penetrations of retractor and depressor motor neurons were made to test for the divergence of a same afferent to both pools of neurons. We found that some afferents excite either retractors or depressors only, whereas others connect with both pools (Fig. $5 G$ ).

All retractor and depressor motor neurons tested were excited by at least some of the canal afferents located on any of the pulvilli. By contrast, the levator tarsi motor neuron was always inhibited by canal afferents (Fig. $5 D$ ). Afferent spikes, however, did not give rise to 1:1 IPSPs after a constant latency, indicating the presence of at least one layer of intercalated interneurons (Fig. 5, inset).

\section{IIairs (trichoid sensilla)}

The pulvilli are devoid of hairs, but the unguis always bears about 8 pairs of long $(100-300 \mu \mathrm{m})$ hairs laterally. Two pairs always point ventrally (Fig. $1 B$ ) and could signal contact with the ground during walking. Spikes from either of these 2 posterior hair afferents are followed 1:1 by EPSPs in a slow retractor unguis motor neuron (Fig. 6A). The unitary EPSPs are 1.5-2 $\mathrm{mV}$, as recorded in the soma (Fig. $6 A$ ), do not facilitate (Fig. 6 , $A, B)$, but can evoke motor spikes. The EPSPs occur with a constant central latency of between 1.4 and $1.8 \mathrm{msec}$ (Fig. $6 \mathrm{C}$ ), indicating a direct connection. Hairs from the anterior pair on the unguis had the same excitatory effect on this motor neuron, but surrounding hairs were ineffective. These connections were found only with one slow retractor, but anatomical evidence suggests that other retractor motor neurons could also receive direct hair inputs (see below, Figs. $3 E$ and 13).

The ungual hairs showed no obvious effect on the depressor and levator motor neurons. Hairs on the lateral-dorsal surface of the 3 tarsal segments and arolium, however, mediate a strong levation reflex, in which the levator is excited via nonspiking local interneurons (Laurent and Burrows, 1988), and some of the depressors are inhibited by barrages of IPSPs caused by interposed inhibitory (spiking) interneurons.

Two distinct effects of tarsal hairs can thus be discerned. Ventrally oriented hairs on the unguis directly excite a retractor, whereas the dorsal and lateral hairs on the tarsus indirectly excite the levator and inhibit the depressors. 

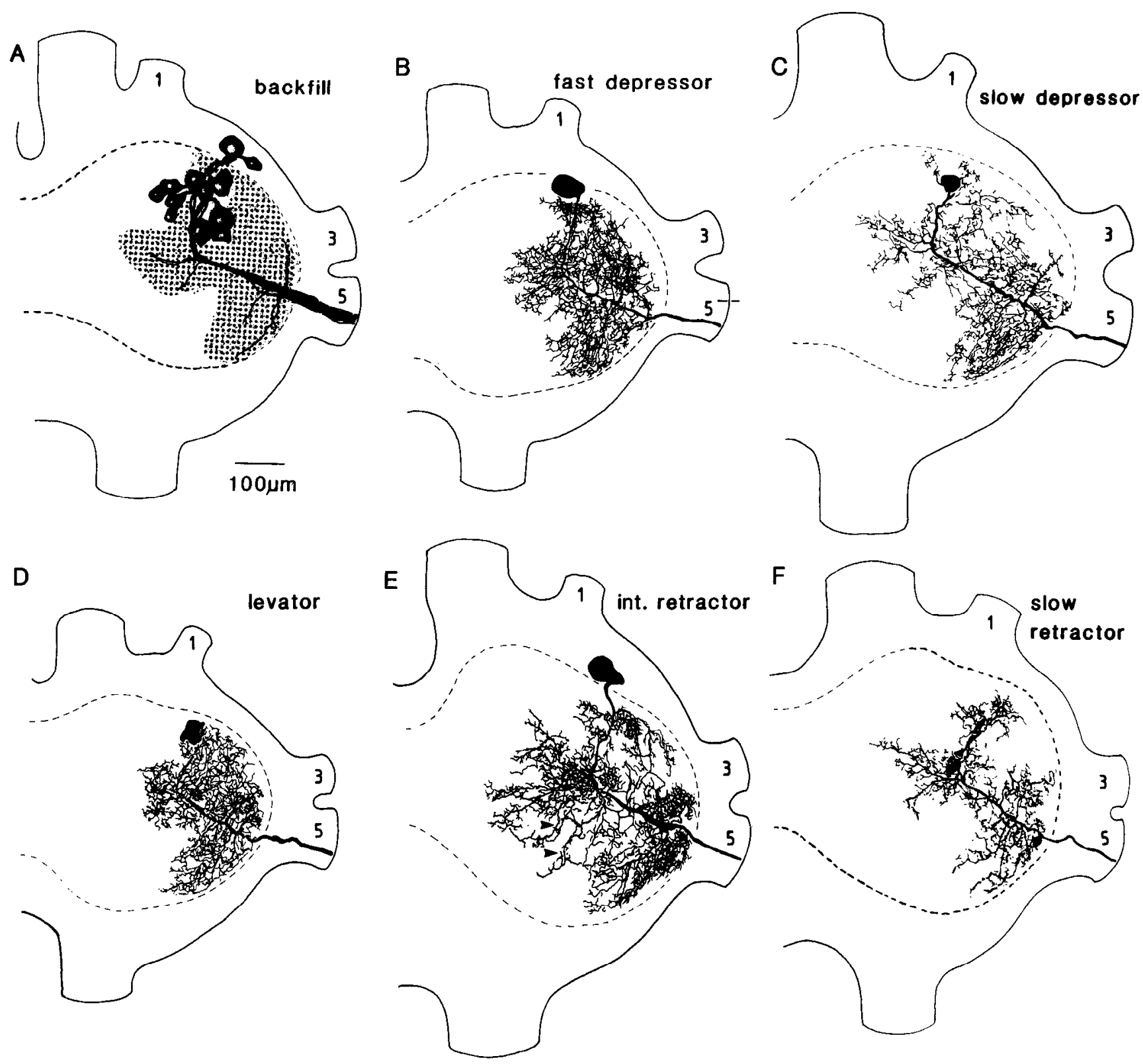

Figure 3. Tarsal motor neurons, as viewed dorsally in whole mounts. $A$, Backfill of N5B2a3 and the nerve to the proximal retractor unguis muscle. This backfill, which should reveal all individuals in the 3 pools of tarsal motor neurons, shows a cluster of 12 somata, the closely running primary neurites, and the lateral extent of the arborizations in the neuropil (dotted area). $B-F$, Intracellular stains (cobalt) of individual motor neurons in the 3 pools. In $E$, branches of an intermediate (int.) retractor unguis which arborize in the ventral neuropil are indicated with arrowheads (see Fig. $13 F) .1,3,5$, peripheral nerves. Anterior is up.

\section{Tibial spurs (campaniform sensilla)}

On the ventral surface of the tibia, there are 2 rows (anterior and posterior) of movable spurs (Fig. $7 A$ ). Each spur has one campaniform sensillum at its dorsal base (Fig. $7 B$ ), which is supplicd by a single afferent (Fig. 7C). This afferent is excited by movement of the spur and can respond tonically for several seconds. When standing on a horizontal surface, the most distal spurs do not touch the ground (Fig. 7A) and their afferents will remain silent. By contrast, if the tibiotarsal angle is greater than about $110^{\circ}$ (Fig. 1) or if the tarsus encounters rough terrain during walking, the 2 pairs of distal spurs will be deflected, the posterior ones at the beginning of the stance phase and the anterior ones at the end. Finally, the tibial spurs are deflected when the animal climbs up narrow objects (e.g., branches in its natural habitat), grasping the substrate between left and right tibiae.

Spikes from the afferent of the second posterior spur evoke constant depolarizations in an intermediate depressor motor neuron. The amplitude and duration of the depolarization vary with the strength and velocity of the stimulus (Fig. $7 D$ ). These depolarizations are due to summating EPSPs evoked by the afferent spikes after a constant central delay of about $1 \mathrm{msec}$ (Fig. 7, E, F). A depressor excited by one spur is always also excited by all the other spurs in its row. For example, the 4 distal posterior spurs all evoke an EPSP in the same (slow) depressor, after a central latency of 1-1.5 msec (Fig. 7, $F$ and Gi-iii). The amplitude of the EPSPs evoked by the different spur 

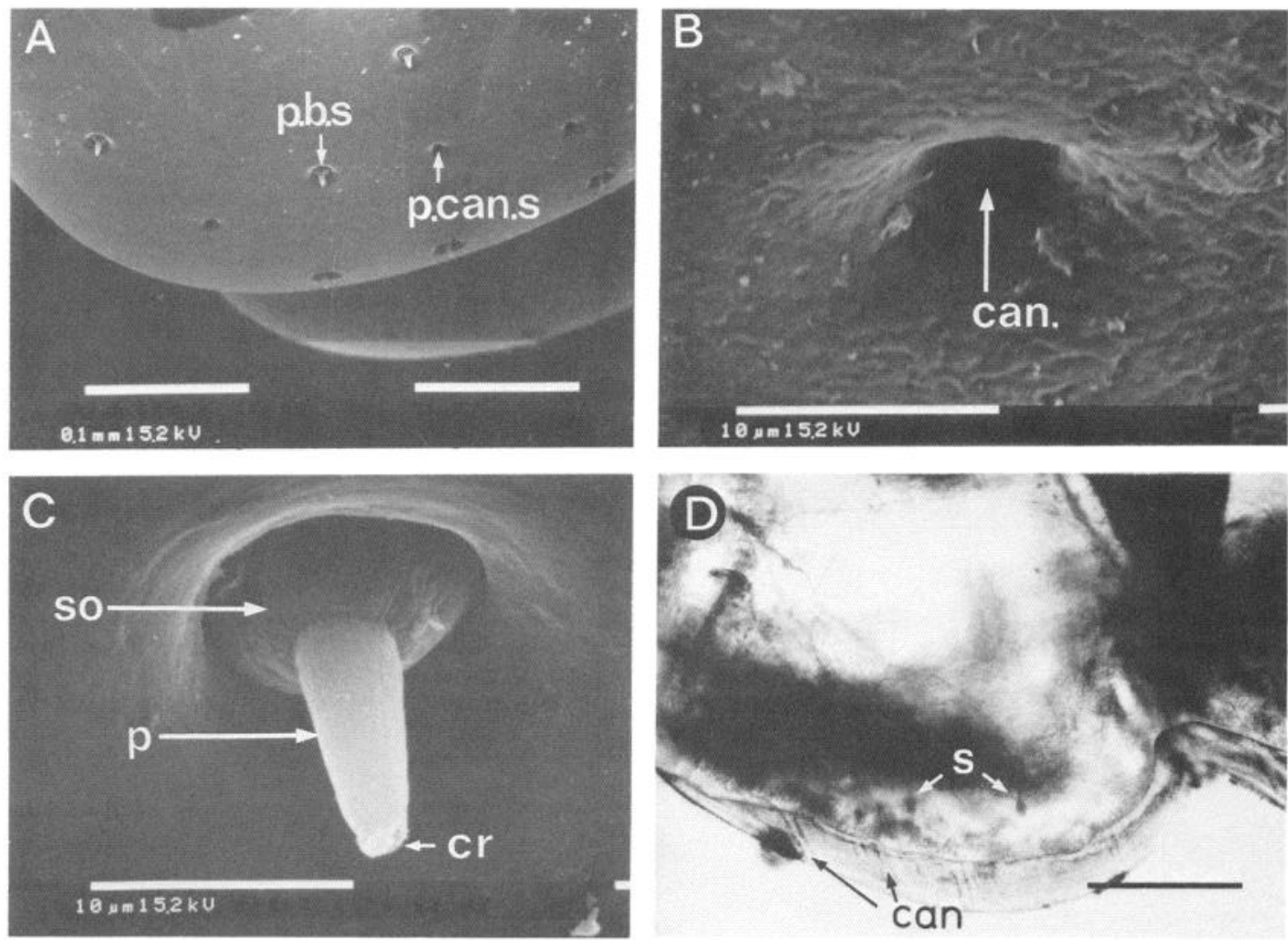

Figure 4. Ventral exteroceptors on the tarsus. A, Anteroventral view of the first pair of pulvilli. The surface is devoid of hairs and bears 2 types of receptors: pulvillar canal sensilla (p.can.s.) and pulvillar basiconic sensilla (p.b.s.). Each is about $60-90 \mu \mathrm{m}$ distant from its neighbors, giving a density of about $400-500 \mathrm{~mm}^{-2}$. B. Higher magnification of the external opening (can., canal) of one pulvillar canal sensillum. $C$, Higher magnification of one pulvillar basiconic sensillum, with its socket $(s o)$, smooth peg $(p)$, and crest $(c r)$. D. Each canal is supplied by a single sensillum $(s)$, here backfilled from N5B2b. The pulvillar basiconic sensilla have one trichogen cell and 6 associated neurons at their base (personal observation and Kendall, 1970), suggesting that they subserve chemo- rather than mechanoreceptive functions. Scale bar $(D), 100 \mu \mathrm{m}$.

afferents of one row, however, and as recorded in the soma of a same motor neuron can vary by a factor 2 (Fig. $7 G$ ). No strong correlation was found between the rank of a spur in a row and the amplitude of the EPSP it evoked. In all animals but 2, both rows of spurs had an excitatory effect on the depressor motor neurons. In one animal, however, a depressor was unaffected by any of the spurs, and in the other, one depressor was excited only by the anterior row.

The spikes from the spur afferents evoke barrages of IPSPs in the levator (Fig. $7 D$ ) and retractor motor neurons, sometimes so reliably that they can be revealed by signal averaging (Fig. $7 H$ ). The IPSP evoked by the second posterior spur afferent, for example, occurs about $2 \mathrm{msec}$ later that the EPSP in a fast depressor motor neuron recorded simultaneously, indicating that it is caused by at least one interposed inhibitory interneuron. In Figure $7 \mathrm{H}$, the resting potential of this interneuron was presumably just at spike threshold, explaining the sharp onset of the averaged IPSP.

\section{Movement sensitivity}

The tarsal movements about the tibia are monitored by 2 principal proprioceptors (Fig. $8 A$ ): the tibiotarsal chordotonal organ and a multipolar sensillum (see Fig. $1 B$ ).

The chordotonal organ comprises about 35 afferent neurons, each of which encodes certain parameters (e.g., direction, velocity) of the movement or the position of the tarsus (Fig. 8A). Depressing the tarsus from $100^{\circ}$ to $170^{\circ}$ with respect to the tibia activates a group of chordotonal afferents, excitates the levator tarsi, and inhibits several depressor motor neurons spiking tonically before the movement (Fig. $8 B$ ). During the maintained depression, the levator continues to spike, but at a decreasing rate, until the following imposed levation (Fig. $8 B$ ). This levation activates a new set of chordotonal afferents, exciting the depressors and inhibiting the levator (Fig. $8 B$ ). This negative feedback (resistance reflex) can also be seen if the movement is caused by motor neuron activity (Fig. 8, $C, D$ ). Tonic spikes in the levator tarsi are each followed by a large compound EPSP in an intermediate depressor and a pronounced hyperpolarization in the levator itself (Fig. 8C). If the movements caused by each levator spike are prevented, the depolarization in the depressor and the hyperpolarization in the levator disappear. Moreover, the latency between the spikes in the levator and the depolarization in the depressor is greater than $13 \mathrm{msec}$, thus ruling out a direct central effect. These effects are therefore due to proprioceptive feedback from the tibiotarsal joint. A pulse of depolarizing current injected in the levator evokes a levation, which then excites the depressor and inhibits the levator by sensory feedback (Fig. $8 D$ ). The resulting depression in turn causes the feedback excitation of the levator and inhibition of the depressors (Fig. $8 D$ ). The servosystem (depressors-proprioceptors-levator) then oscillates, in a manifestation of a "hunting" phenomenon (Hoyle and Burrows, 1973). What then is the underlying central connectivity between the afferents and the motor neurons? 


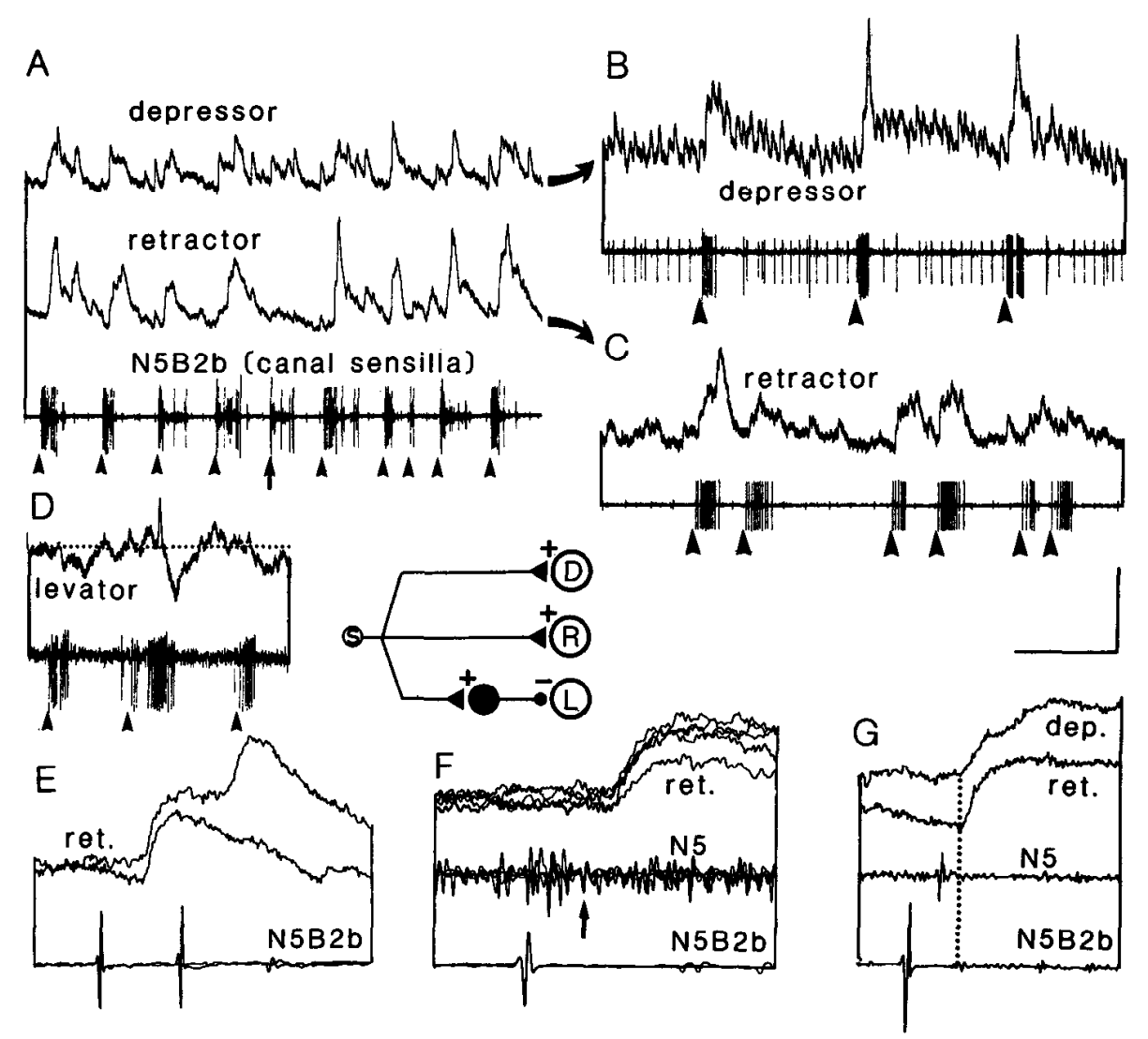

Figure 5. Central connections made by the pulvillar canal sensilla afferents. $A$, A burst of p.can.s. spikes evoked by touch of about $600 \mu \mathrm{m}^{2}$ (arrowheads) and recorded in N5B2b cause a depolarization simultaneously in a depressor and a retractor motor neuron. The arrow indicates one stimulus that evokes a reflex response in the depressor only. $B$. Stimulating a single canal afferent mechanically (arrowheads) depolarizes a depressor. The tonic unit (bottom trace) is the tibial multipolar sensillum afferent (see Fig. 10). C, A different p.can.s. evokes a depolarization in a retractor motor neuron. $D$, p.can.s. spikes hyperpolarize the levator motor neuron. Dotted line indicates "average" resting potential. $E$, Two sweeps triggered from a p.can.s. spike. Each spike evokes an EPSP in a retractor motor neuron. There is no homosynaptic facilitation. $F$, Five superimposed sweeps triggered from a p.can.s. spike, also recorded from N5 (arrow, middle trace). The EPSP in the retractor is evoked after a constant central latency of about $1.5 \mathrm{msec}$. $G$, A p.can.s. afferent evokes an EPSP simultaneously in a retractor and a depressor. Signal averages of 32 sweeps triggered from the afferent spike in N5B2b. Inset, Diagram of the connectivity between the canal afferents and the 3 pools of tarsal motor neurons. Depressors $(D)$ and retractors $(R)$ are directly excited. The levator $(L)$ is inhibited by at least one interposed inhibitory interneuron. Horizontal scale bars: 0.5 $\sec (A-C), 1 \mathrm{sec}(D), 17 \mathrm{msec}(E), 8.5 \mathrm{msec}(F)$, and $20 \mathrm{msec}(G)$; vertical scale bars: depressor $(A, B), 4 \mathrm{mV}$; levator $(D), 8 \mathrm{mV} ;$ retractor, $8 \mathrm{mV}$ $(A), 4 \mathrm{mV}(C)$, and $0.8 \mathrm{mV}(E, F)$.
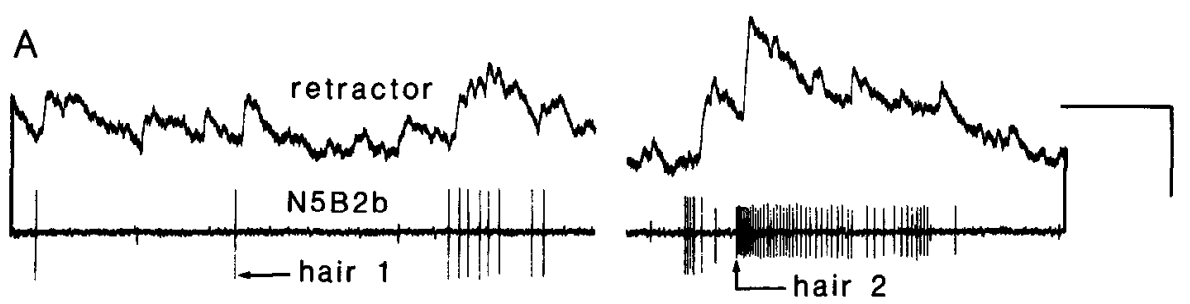

B

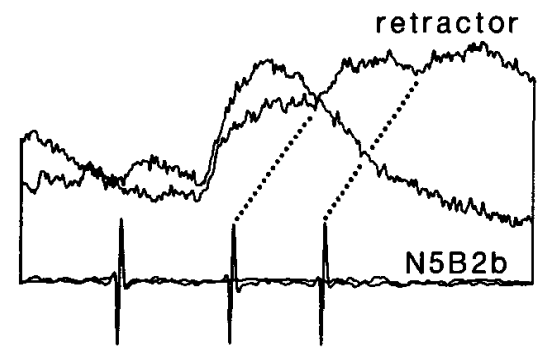

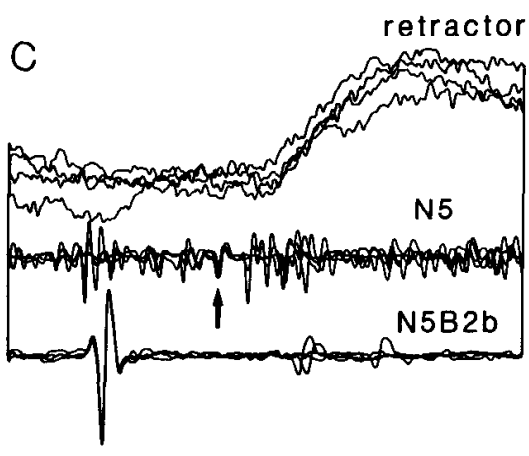

Figure 6. Ungual hairs connect directly with a slow retractor unguis motor neuron. $A$, Hairs 1 and 2 (displaced individually and successively) evoke unitary EPSPs in the motor neuron. $B$, Each hair afferent spike causes a single EPSP. There is no homosynaptic facilitation. $C$, Superimposed sweeps triggered from one hair afferent spike also recorded in nerve 5 (arrows, middle trace). The central latency to the evoked EPSP is constant, at about $1.6 \mathrm{msec}$. The projections of this motor neuron are shown in Figure 13E. Horizontal scale bars: $0.25 \mathrm{sec}(A), 17 \mathrm{msec}(B)$, and $8.5 \mathrm{msec}(C)$; vertical scale bars: retractor, $4 \mathrm{mV}(A)$ and $1.5 \mathrm{mV}(B, C)$. 

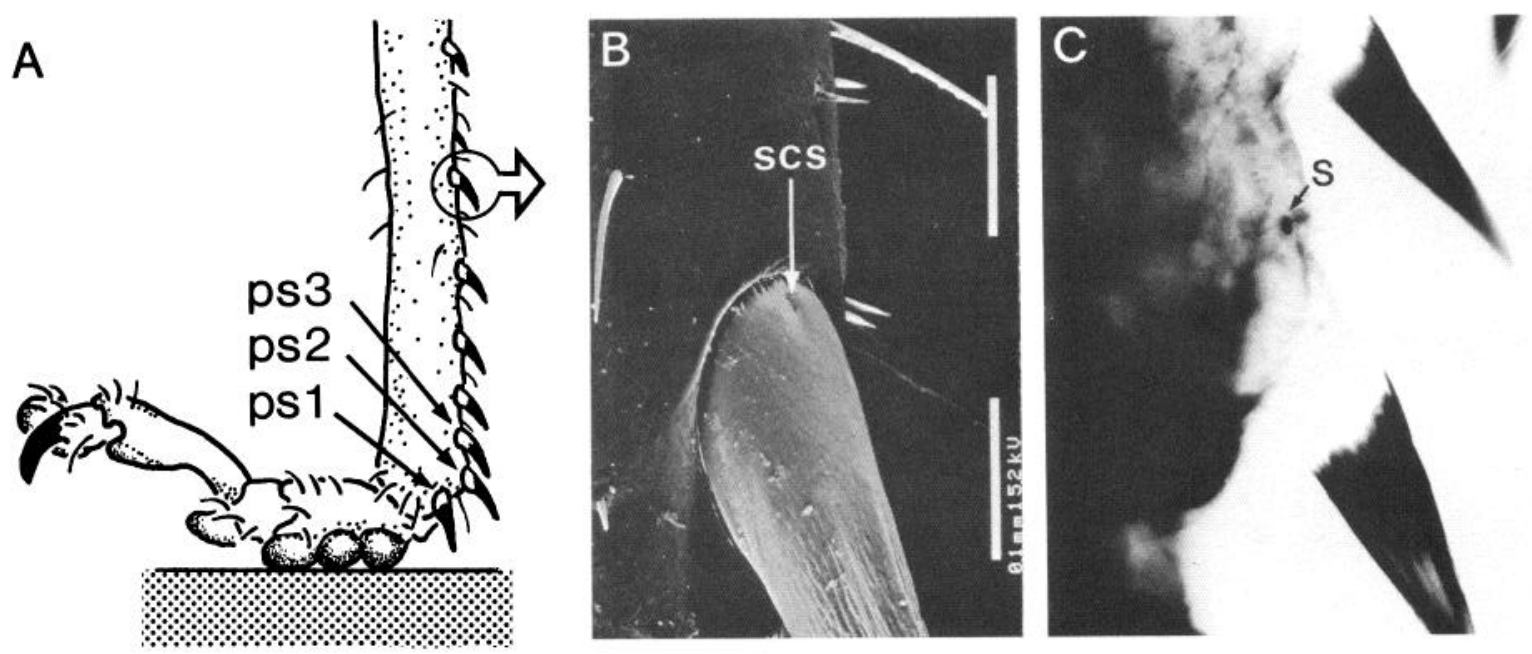

$\mathrm{D}$

levator
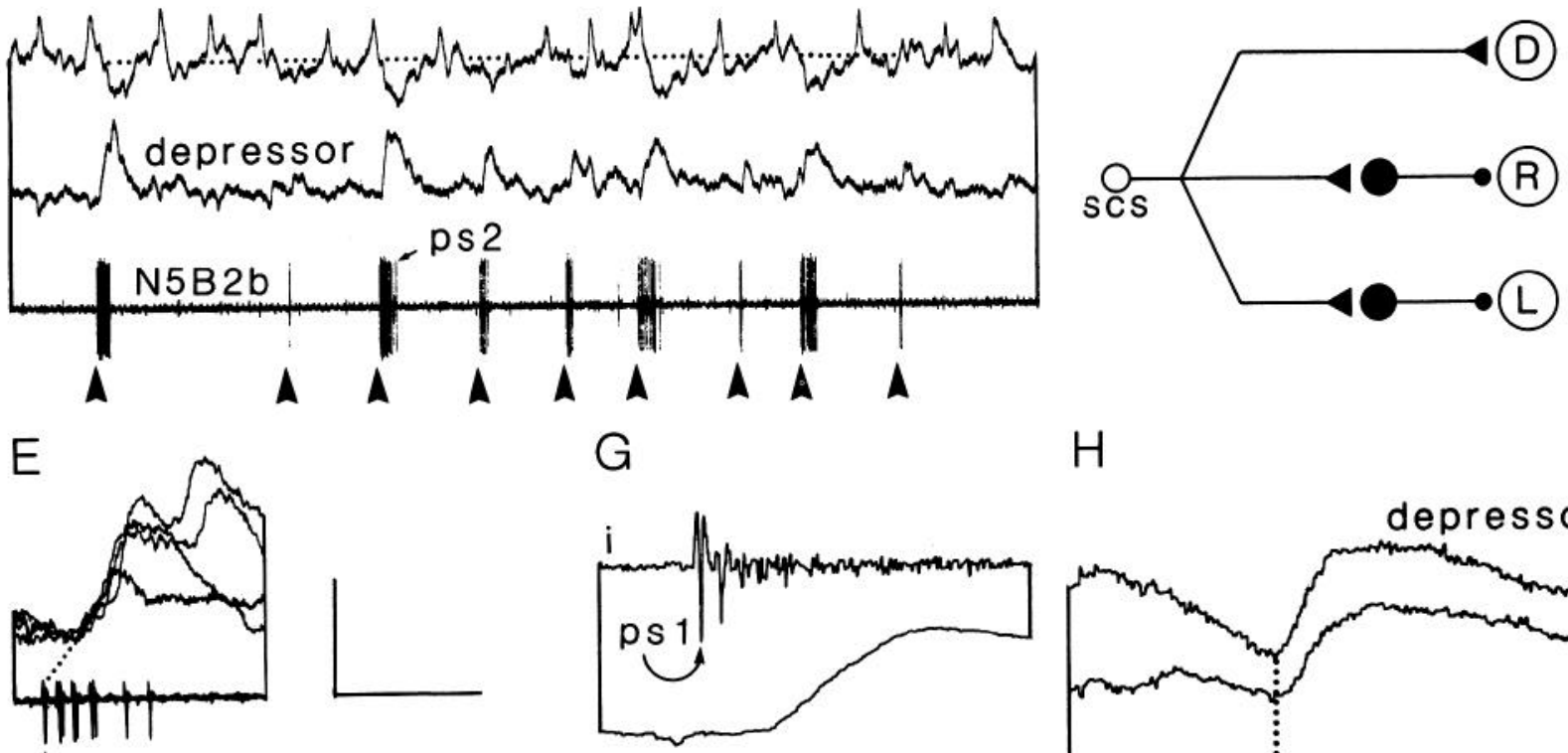

G

$\mathrm{H}$
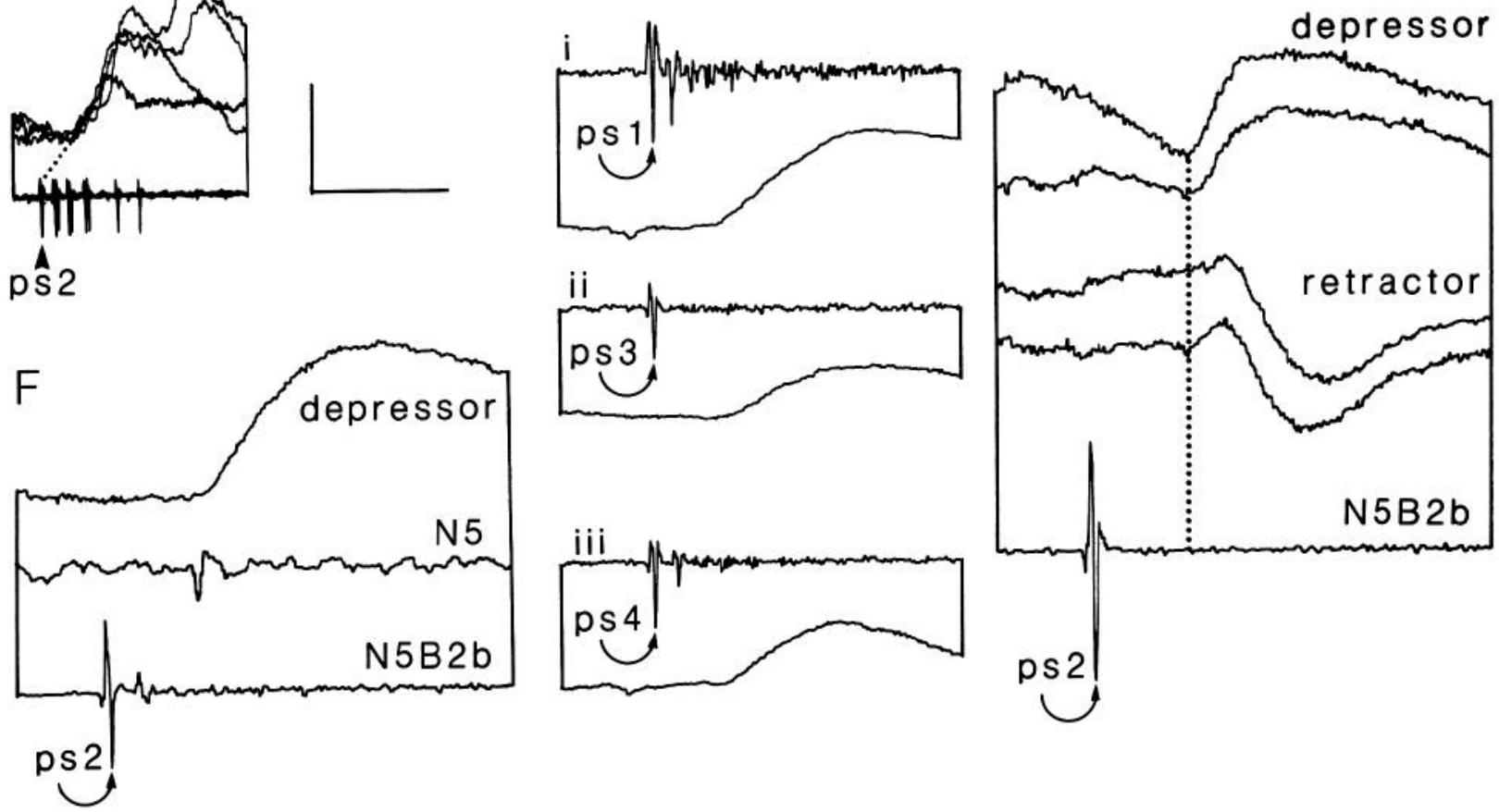

Figure 7. Tibial spurs and their connections with the tarsal motor neurons. A, The spurs are movable spines along the ventral tibia. ps 1-4; posterior spurs $1-4 . B$, SEM picture of one spur, with the spur campaniform sensillum (scs) at its base. $C$, The single afferent $(s)$ lying beneath the campaniform structure, filled with cobalt from N5B2b. Magnification as in $B . D$, ps2 afferent spikes (arrowheads) evoke a depolarization in a depressor and a hyperpolarization in the levator. $E$, Multiple sweeps triggered from the spike of ps2 (arrowhead): An EPSP follows in a depressor with a constant latency. $F$, ps 2 afferent spikes evoke EPSPs in a depressor after a central latency of about $1 \mathrm{msec}$. Signal average of 128 sweeps. $G$, ps1, 3 and 4 , like ps $2(F)$, all evoke an EPSP in the same depressor. Each trace is an average of 64 sweeps. $H$, ps2 afferent spikes evoke an IPSP in a retractor, which occurs about $2 \mathrm{msec}$ later than the EPSP in a depressor recorded simultaneously. Each trace is a signal average of 128 sweeps. Inset, Diagram symbolizing the connections between the spur campaniform sensilla ( $s c s)$ and the tarsal motor neurons. Horizontal scale bar: 0.5 sec $(D)$, 50 msec $(E), 14 \mathrm{msec}(F, H)$, and $18 \mathrm{msec}(G)$; vertical scale bar: $(D)$ levator, $8 \mathrm{mV}$; depressor, $4 \mathrm{mV}$; $(E)$ depressor, $1.5 \mathrm{mV}$. 

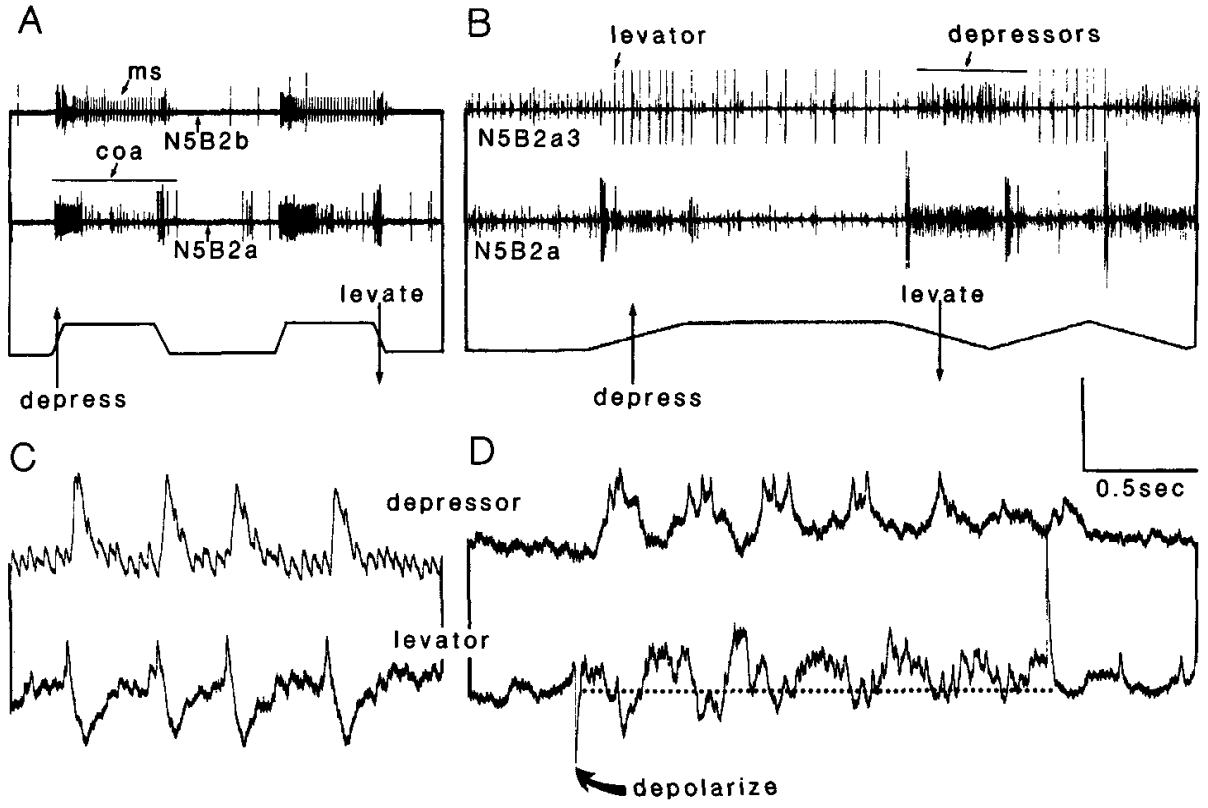

Figure 8. Proprioceptive monitoring of tibiotarsal movements. $A$, An imposed depression activates a tibiotarsal multipolar sensillum ( $m s$ ) and chordotonal organ afferents $(c o a)$. $B$, Movements imposed on the tarsus lead to the reflex excitation of the levator and inhibition of the depressors during depression and inhibition of the levator and excitation of the depressors during levation. $C$, Spikes in the levator motor neuron are followed by a feedback depolarization in a depressor and a hyperpolarization in itself. $D$, Injecting a pulse of steady depolarizing current in the levator evokes an oscillation of the tarsus, whereby a depressor and the levator are excited in antiphase. Horizontal scale bar: $0.5 \sec (A-D)$; vertical scale bar: $C, 8 \mathrm{mV} ; D, 4 \mathrm{mV}$ (depressor) and $8 \mathrm{mV}$ (levator).
Individual chordotonal afferents were selectively stimulated with intracellular microelectrodes inserted in their cell body, while the response of tarsal depressor and levator motor neurons was simultaneously recorded intra- and extracellularly (Fig. 9). Releasing an afferent from an applied hyperpolarization evokes a burst of spikes, which in turn causes a subthreshold depolarization in a fast depressor, a burst of spikes in a slow depressor, and the inhibition of the tonically spiking levator motor neuron (Fig. 9). The selective activation of one afferent alone is therefore sufficient to evoke a reflex movement by divergent connections to at least 2 depressors, and probably one interneuron at least to mediate the inhibition of the levator. Individual EPSPs are sometimes visible in a depolarization of the fast depressor evoked by a group of afferent spikes (Fig. 9B). Each afferent spike can then be scen to cvokc an EPSP, after a consistent central latency of 1-1.4 msec (Fig. 9C).

The multipolar sensillum, situated dorsally at the distal end of the tibia (Fig. 10, $A, B$ ) is excited by the full depression $\left(140^{\circ}-\right.$ $180^{\circ}$ ) of the tarsus (Fig. 10A). A movement in this range imposed on the tarsus with the chordotonal organ intact evokes a depolarization in the levator and a hyperpolarization in an intermediate depressor (Fig. 10C). Retractor motor neurons are unaffected (Fig. 10D).

To assess the contribution of the multipolar sensillum to the reflex excitation of the levator, the dorsal nerve N5B2a, carrying the chordotonal afferents, was cut, leaving the multipolar sensillum as the only proprioceptor signaling tibiotarsal movement (Fig. 10E). The reflex was considerably reduced in strength, so
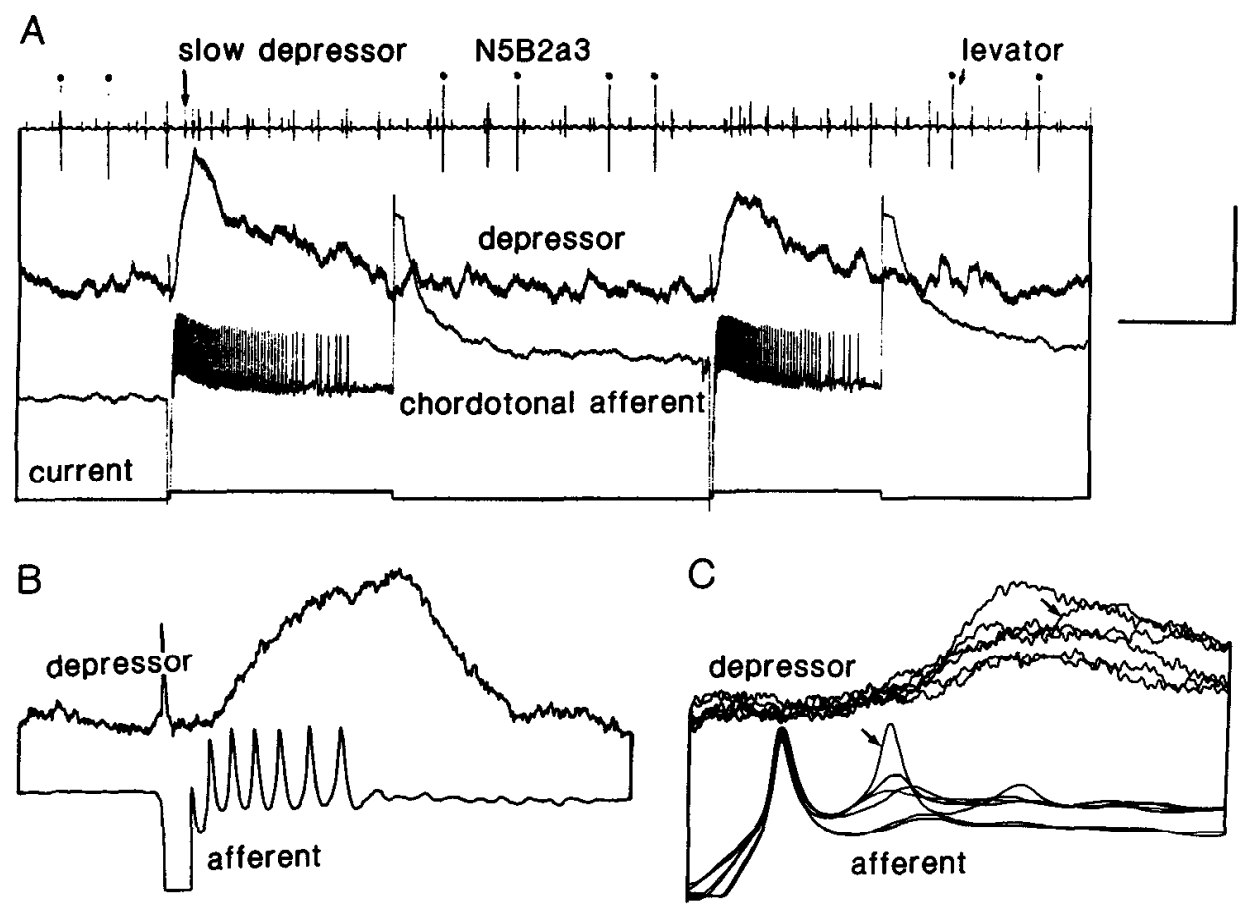

Figure 9. Monosynaptic connection between chordotonal afferents and depressor motor neurons. $A$, Releasing a chordotonal afferent cell body from a steady hyperpolarization to make it spike evokes a subthreshold depolarization in a fast depressor ( 2 nd trace), a burst of spikes in a slow depressor, and the inhibition of the levator (dots, top trace). B. Faster sweep of an electrically evoked burst of afferent spikes and the resulting motor neuron depolarization. $C$, Multiple sweeps triggered from afferent spikes evoked by current injection. Each spike is the first or second of a burst and evokes an EPSP in the motor neuron with a constant latency. Arrows, A later afferent spike and the EPSP it crokcs. The varying amplitude of the EPSPs may indicate different levels of quantal release. Horizontal scale bar: $A, 250 \mathrm{msec} ; B, 29$ msec; and $C, 8.5 \mathrm{msec}$; vertical scale bar: depressor, $5 \mathrm{mV}(A), 3 \mathrm{mV}(B)$, and $2.5 \mathrm{mV}(C)$; afferent, $15 \mathrm{mV}(A)$, $12 \mathrm{mV}(B)$, and $10 \mathrm{mV}(C)$. 
A

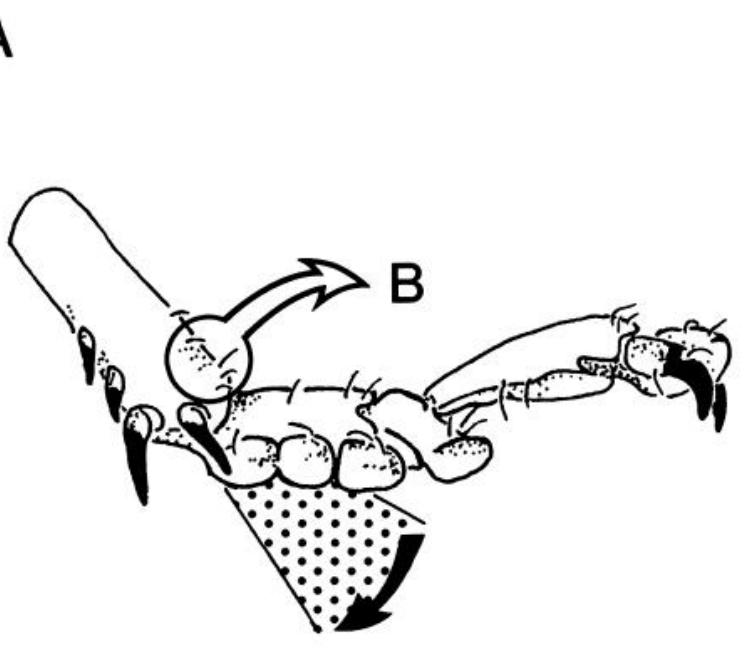

C
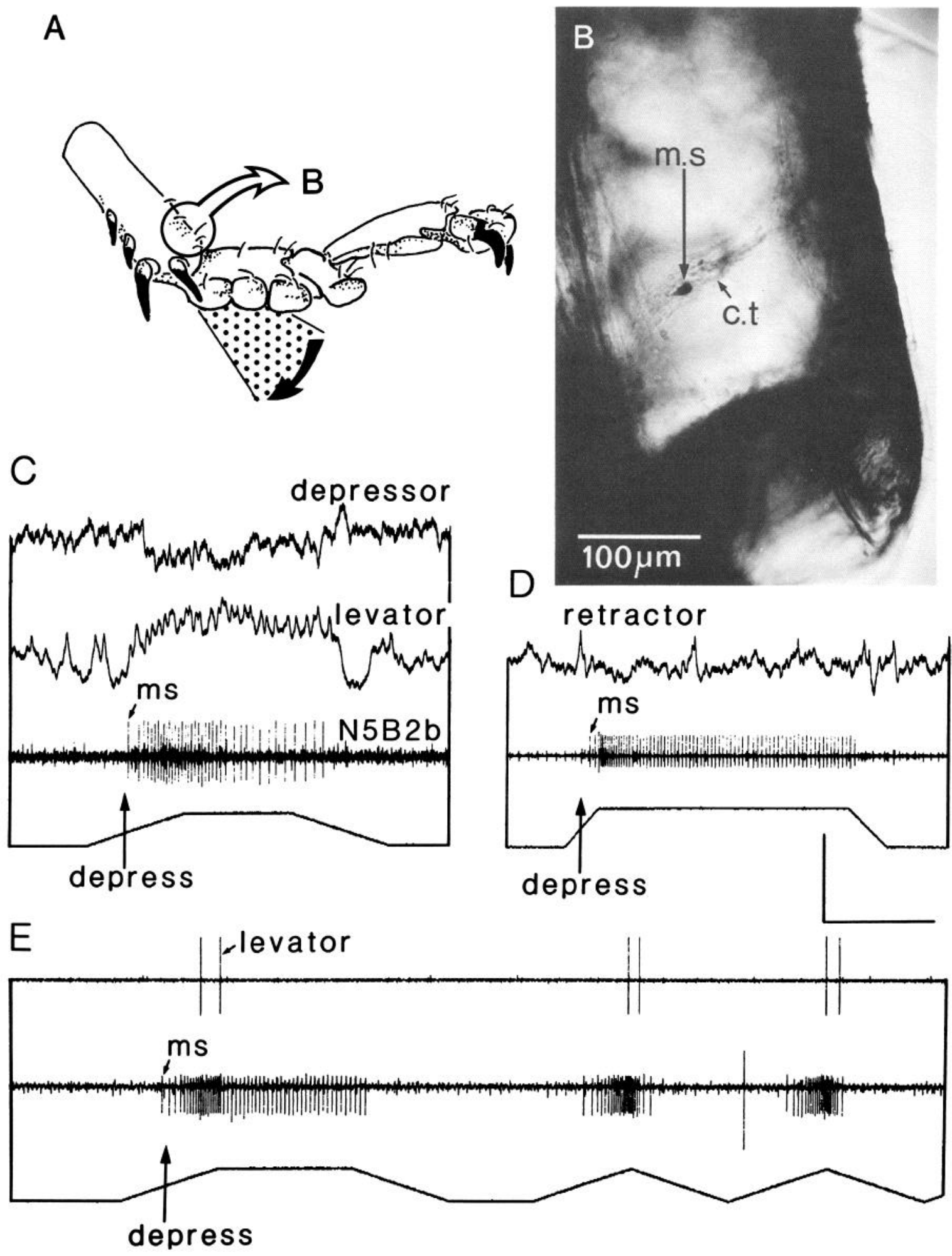

Figure 10. Tibiotarsal multipolar sensillum $(\mathrm{ms})$ contributes to a resistance reflex. $A$, Situated at the dorsal-distal end of the tibia (circle), the sensillum responds to depression, within the range indicated by a stippled area. B. Photomicrograph of the sensillum $(m . s)$ in its strand of connective tissue (c.t), spanning across the joint between the dorsal tibial hypodermis and the tarsus at the level of the levator insertion. The sensillum was filled with cobalt from N5B2b. C, An imposed depression from $130^{\circ}$ to $180^{\circ}$ activates ms, strongly excites the levator, and inhibits a depressor. The chordotonal organ is intact. $D$, The tibiotarsal movements have no effect on a retractor (chordotonal organ intact). $E$, If the chordotonal organ nerve is cut, so that $\mathrm{ms}$ is the only proprioceptor left monitoring tibiotarsal movement, the levator is still excited, although weakly. Horizontal scale bar: $0.5 \mathrm{sec}(C-D)$; vertical scale bar: $(C)$ levator, $8 \mathrm{mV}$; depressor, $4 \mathrm{mV} ;(D)$ retractor, $8 \mathrm{mV}$. 

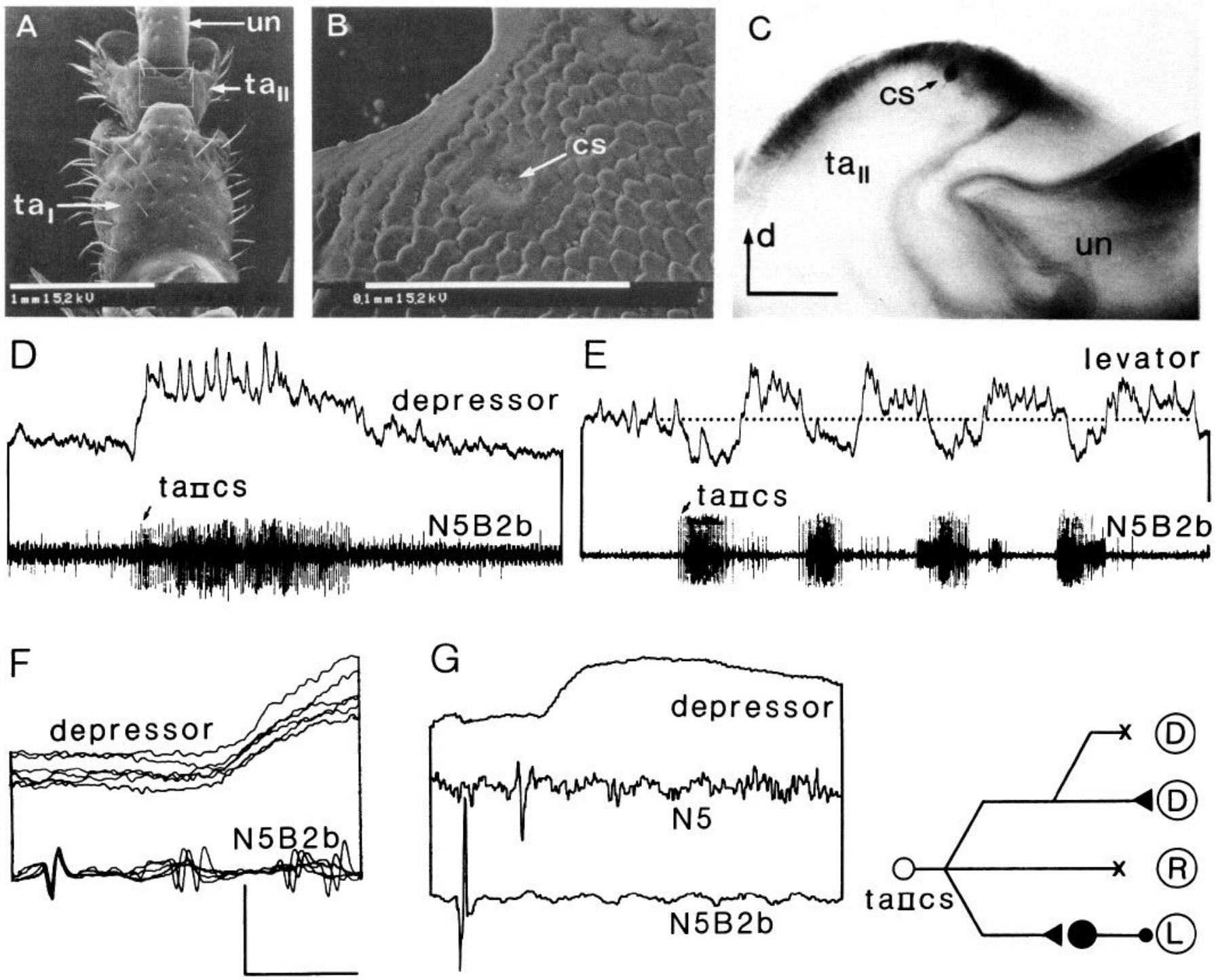

Figure 11. Intrinsic tarsal movements. $A$, Dorsal view of the tarsus. $\mathrm{Ta}_{\mathrm{I}} \mathrm{cs}$ is in the center of the rectangle. un, unguis. $B$, Close-up of the cs. $C$, Photomicrograph of the cs afferent stained from N5B2b. $d$, dorsal. Scale bar, $50 \mu \mathrm{m} . D$, Selective activation of ta ${ }_{\text {II }}$ cs causes a depolarization and spikes in a slow depressor tarsi. $E$, The levator is inhibited. $F$, Multiple sweeps triggered from ta ${ }_{\|} c s$ spikes. An EPSP is evoked after a constant latency in the depressor. $G$, The central latency to the EPSP is about $1.4 \mathrm{msec}$. Signal average of 512 sweeps. Inset; Summary of the connections. Some depressors are excited directly, other depressors and the retractors are unaffected. The levator is indirectly inhibited. Horizontal scale bar: $D$ and $E$, $0.5 \mathrm{sec} ; F, 6.5 \mathrm{msec}$; and $G, 14 \mathrm{msec}$; vertical scale bar: $(D)$ depressor, $8 \mathrm{mV} ;(E)$ levator, $8 \mathrm{mV}$; and $(F)$ depressor, $1.5 \mathrm{mV}$.

that a ramp that would have normally led to $20-30$ spikes in the levator (Fig. 10C), evoked only 2 spikes when the frequency of spikes in the multipolar sensillum reached its maximum (Fig. $10 E$ ). Intracellular recordings from the soma of the levator motor neuron failed to reveal any PSP caused by the multipolar cell spikes, suggesting the absence of a direct connection.

Intrinsic movements of the tarsus appear to be signaled only by external receptors, which are excited when the movement causes the deformation of the cuticle of the next proximal segment. For example, levation of the unguis is monitored by a single campaniform sensillum on the dorsal edge of the second tarsal segment (Fig. 11, $A, B$ ). Its afferent (Fig. 11C) shows phasic and tonic responses to levation of the unguis (Fig. 11, D, E). The selective activation of this campaniform sensillum evokes a depolarization in a slow depressor (Fig. $11 D$ ) and a hyperpolarization in the levator motor neuron (Fig. 11E). The excitation of this and a second depressor is direct, as spikes from the afferent evoke EPSPs in them after a constant central delay of just above $1.4 \mathrm{msec}$ (Fig. 11, F, G). All other depressors tested were unaffected, indicating that this afferent makes a limited set of connections within the depressor pool. None of the retractor motor neurons tested was affected (Fig. $11 \mathrm{H}$ ).

\section{Overlap of the sensory and motor central terminals}

To search for regions of overlap between the arborizations of the sensory and motor neurons, cobalt backfills of individual afferents were made from campaniform sensilla at the base of the spurs (Fig. 12, $A, B$ ) or on the second tarsal segment (taIIcs, Fig. 12C). Attempts in 10 animals to stain the central projections of individual tarsal hairs were unsuccessful. We therefore stained their projections from side branches of nerves $5 \mathrm{~B} 2 \mathrm{a}$ and $\mathrm{b}$ (Fig. $12 D$ ). Transverse sections through the projections of the afferents and motor neurons they excite show an overlap of arborizations in the intermediate and lateral neuropils for the cam- 

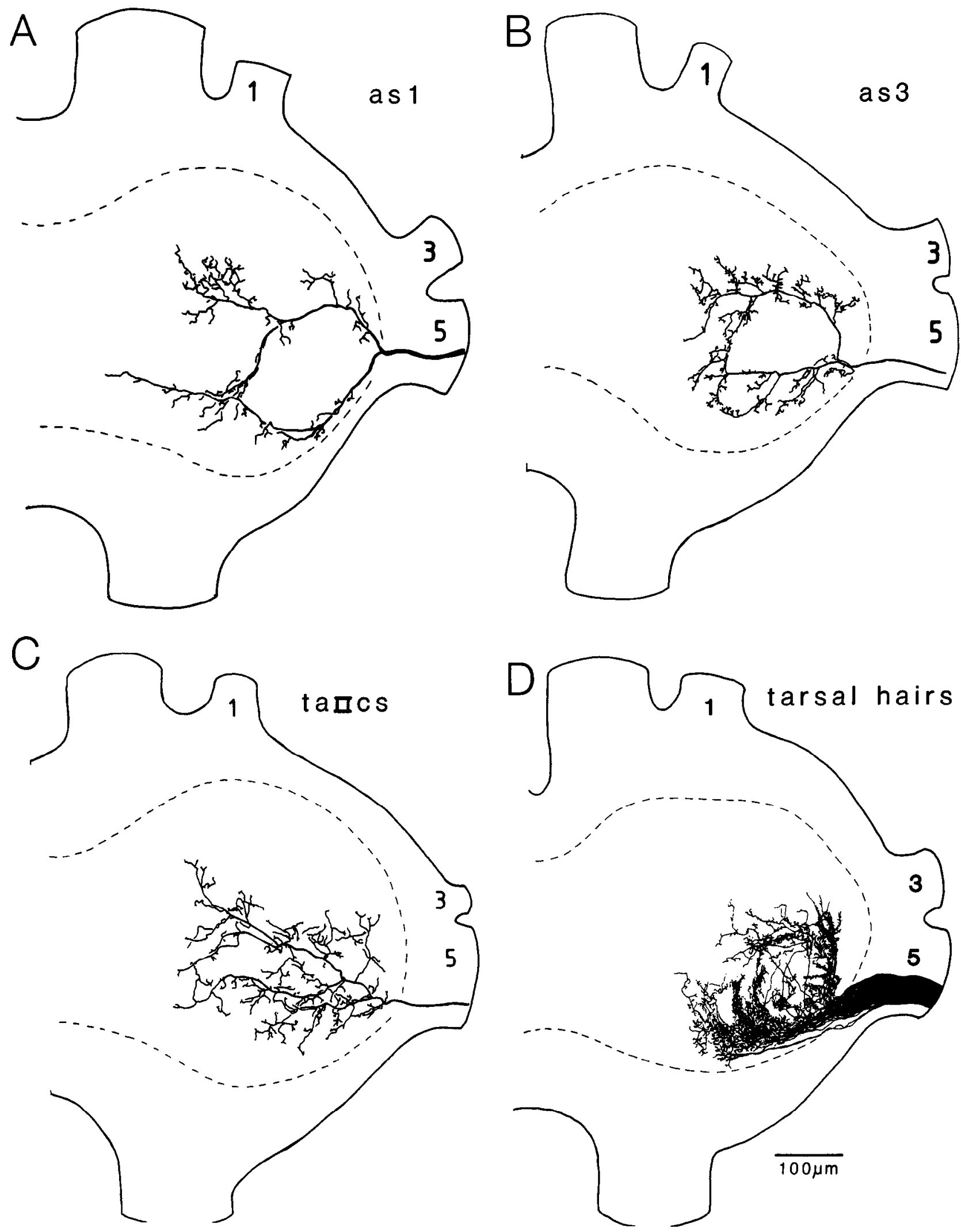

Figure 12. Central sensory projections. A, Anterior spur 1 (asl) campaniform sensillum. B, Anterior spur 3 (as3) campaniform sensillum. The projections of the spur campaniform sensilla (see Fig. 7, $B$ and $C$ ) all show a typical axonal bifurcation at the edge of the neuropil, as seen in other leg campaniform sensilla (Hustert et al., 1981). $C$, Projections of $\operatorname{ta}_{1 \mathrm{II}} \mathrm{cs}$ (see Fig. $11, B$ and $C$ ). $D$, Central projections of about 20 hair afferents on the posterodorsal surface of the tarsus. 

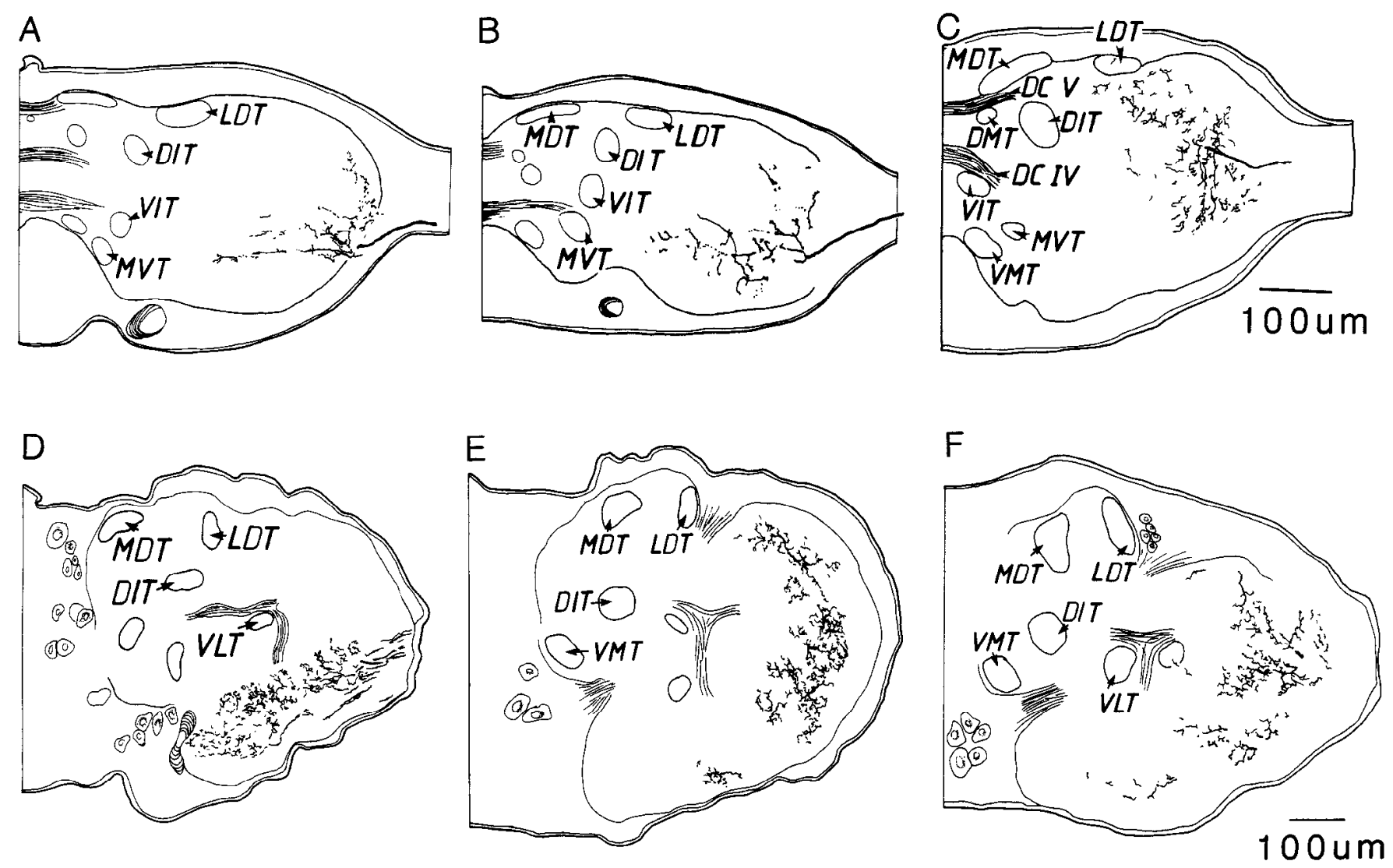

Figure 13. Overlap between the sensory and motor central projections. $A-C$, Transverse section at the level of nerve 5 of the central projections of $(A)$ as 1 (Fig. 12A), $(B)$ ta $_{\mathrm{II}}$ cs (Fig. 12C), and $(C)$ a fast depressor tarsi (Fig. $3 B$ ). This motor neuron is excited by both receptors, and its projections overlap with theirs in the lateral neuropil. $D-F$, Transverse sections at a level just posterior to nerve 5 of the central projections of $(D)$ tarsal hairs (Fig. 12D), $(F)$ a slow retractor unguis (the one recorded in Fig. 6 ), and $(F)$ an intermediate retractor unguis (Fig. $3 E$ ). Direct contact between hair afferents and certain retractor unguis motor neurons is thus possible in the ventral association center and lateral neuropil. Abbreviations (from Tyrer and Gregory, 1982): DCIV and V, dorsal commissures IV and V; DIT, dorsal intermediate tract; $D M T$, dorsal medial tract; $L D T$, lateral dorsal tract; $M D T$, medial dorsal tract; $M V T$, medial ventral tract; $V I T$, ventral intermediate tract; and VMT, ventral median tract.

paniform sensilla (Fig. 13A-C) and in the ventral and lateral neuropils for the hair afferents (Fig. 13D-F). Chordotonal afferents also overlap with depressor and levator motor neurons (Laurent, 1987a). Direct sensorimotor connections are therefore possible.

\section{Involvement of nonspiking interneurons}

In the light of the recent finding that premotor nonspiking local interneurons receive direct inputs from mechanosensory afferents (Burrows et al., 1988; Laurent and Burrows, 1988), we tested the possibility that nonspiking local interneurons presynaptic to the depressor and levator motor neurons might also be affected by the tarsal afferents.

A nonspiking local interneuron with an excitatory effect on a depressor is excited by the pulvillar afferents (Fig. 14A). A $3 \mathrm{nA}$ pulse of depolarizing current injected into this interneuron doubles the frequency of spikes in a slow depressor motor neuron (Fig. 14Ai). The interneuron is itself depolarized by a barrage of EPSPs when pulvillar afferents are excited (Fig. 14 $\mathrm{Ai}$, arrowheads). Signal averaging shows that a pulvillar afferent evokes an EPSP in the interneuron with a latency identical to that in depressor and retractor motor neurons (compare Figs. 5 and 14Aii).

A nonspiking local interneuron presynaptic to the levator is inhibited by the spur afferents (Fig. 14B). A pulse of depolarizing current injected into this interneuron causes the previously silent levator tarsi motor neuron to spike (Fig. 14Bi). Spikes from the campaniform sensillum of the first posterior spur evoke a barrage of IPSPs in the interneuron (Fig. 14Bi, arrowheads). Signal averaging reveals that the IPSP occurs about $3.5 \mathrm{msec}$ later than the EPSP evoked in a fast depressor motor neuron recorded simultaneously (Fig. 14Bii). The inhibition is therefore mediated by at least one intercalated inhibitory interneuron.

A nonspiking interneuron with an excitatory effect on the levator is inhibited by tibial extension and tarsal levation (Fig. $14 C)$. The inhibition during tarsal levation is due to several presynaptic spiking local interneurons, one of which is recorded simultaneously in Figure 14C. Its spikes cause 1:1 IPSPs in the nonspiking interneuron, with a constant latency of less than 1 msec (Fig. 14Cii).

The control exerted by the interposed nonspiking interneurons on the gain of the sensorimotor pathways can be demonstrated by manipulating their membrane potential during an imposed stimulus. Consider an interneuron excited by spur campaniform sensilla (Fig. 15A), which has an inhibitory effect on a coxal motor neuron. A pulse of depolarizing current injected into this interneuron decreases the tonic frequency of spikes in the motor neuron (Fig. 15B). If a spur is moved while the interneuron is at normal membrane potential, a burst of 
Figure 14. Polysynaptic pathways involving nonspiking local interneurons. $A i$, a nonspiking interneuron excites a slow depressor (spikes indicated by dots) when depolarized by current injection and is depolarized by pulvillar canal sensilla afferents (arrowheads). Aii, A canal sensillum evokes an EPSP in this interneuron. Two successive signal averages of 64 sweeps. Bi, A second interneuron, with an excitatory effect on the levator, is hypcrpolarized by spikes from the afferent of a tibial spur (arrowheads). Bii, This afferent evokes an IPSP in the interneuron 3-4 msec later than an EPSP in a depressor recorded simultaneously. Each trace is an average of 64 sweeps. $C$, The inhibition is caused by spiking local interneurons. $i$, This nonspiking interneuron excites the levator and is hyperpolarized by an imposed tibial extension or a tarsal levation (arrowheads). This inhibition is caused by several spiking local interneurons, one of which was penetrated simultaneously (bottom trace). ii, Superimposed sweeps triggered from the spike of the spiking interneuron show that each spike evokes an IPSP in the nonspiking interneuron after less than 1 msec. Horizontal scale bar: $A i, 0.5$ sec; $A i i, 14 \mathrm{msec} ; B i, 0.5 \mathrm{sec} ; B i i, 14$ msec; $C i, 0.65 \mathrm{sec}$; $C i i, 14.3 \mathrm{msec}$; vertical scale bar: nonspiking interneuron, $10 \mathrm{mV}(A i), 5 \mathrm{mV}(B i), 6.6 \mathrm{mV}(C i)$, and $1 \mathrm{mV}(C i i)$; spiking interneuron, 12 $\mathrm{mV}(C i)$ and $6 \mathrm{mV}(C i i)$.

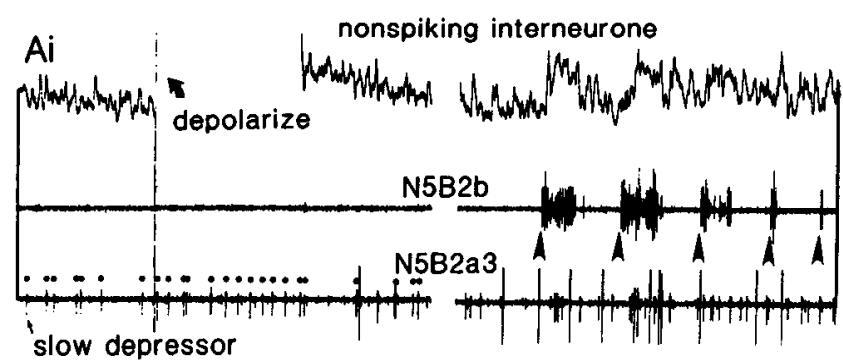

Aii
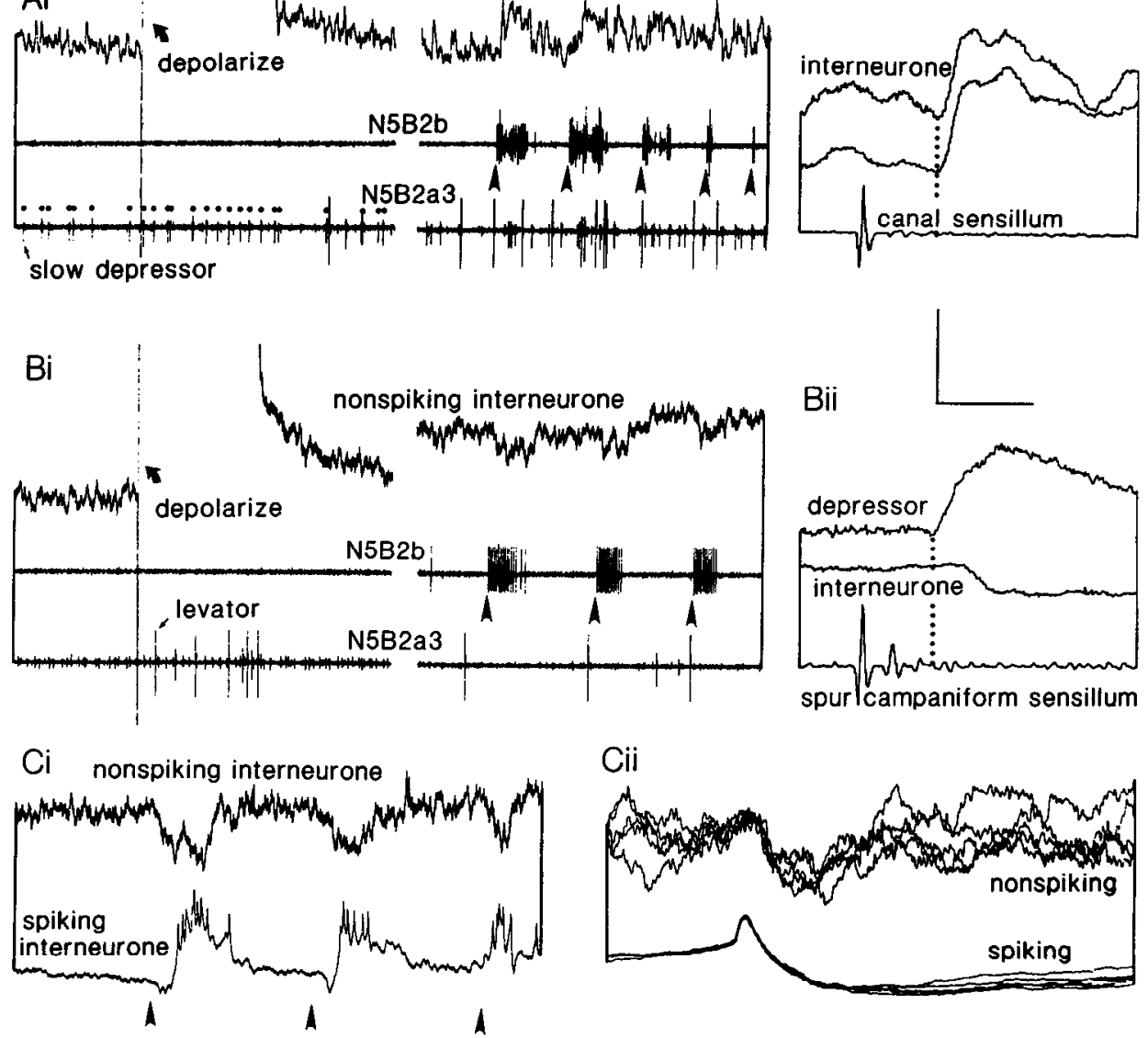

EPSPs is evoked in the interneuron and a hyperpolarization in the motor neuron (Fig. 15C, arrow 1). If the same stimulus is given while the interneuron is held hyperpolarized by a short pulse of current, the amplitude of the evoked depolarization in the interneuron is increased, but the hyperpolarization of the motor neuron is decreased (Fig. 15C, arrow 2.) The likely ex- planation is that the transient increase in transmitter release due to the afferent depolarization depends on the interneuron's basal resting potential (see Burrows, 1980; Reichert et al., 1983). The reflex effects caused by a sensory stimulus to the tarsus will therefore normally depend on the state of the interneurons interposed between the afferents and the motor neurons.

\section{A}
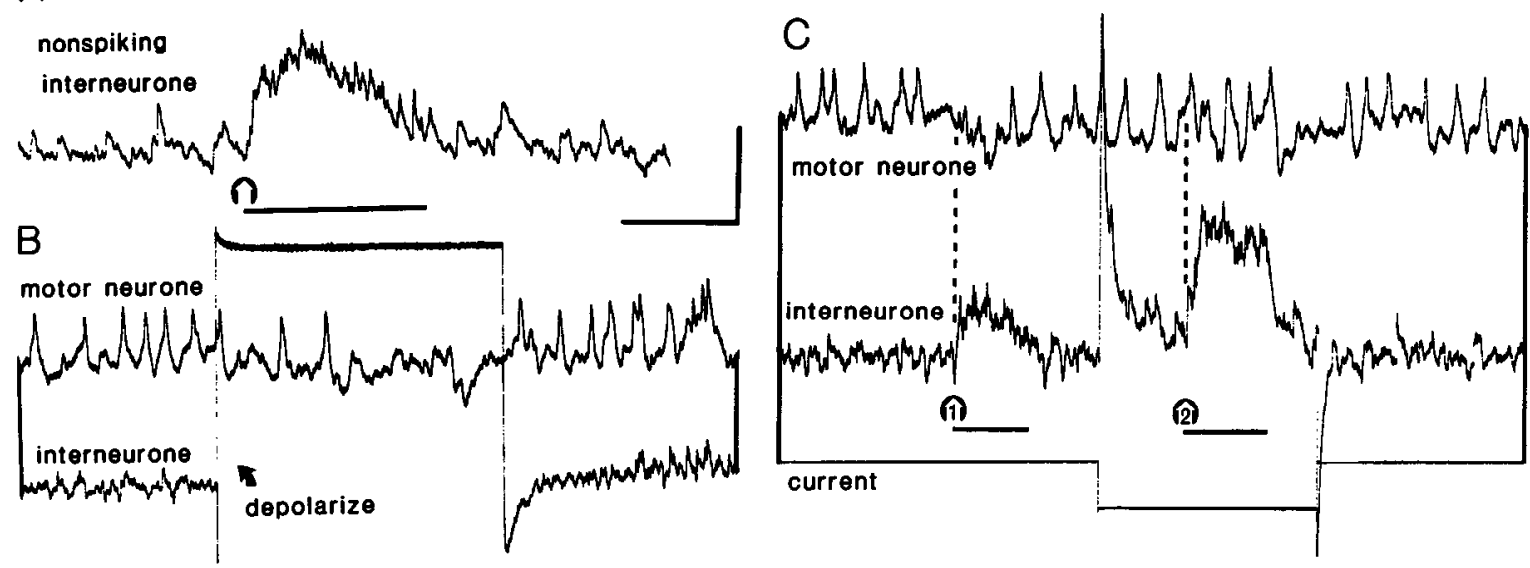

Figure 15. Nonspiking local interneurons control the gain of the sensorimotor pathways. $A$, This interneuron is excited by the anterior spur afferents. Moving one spur (arrow and bar) evokes a barrage of EPSPs in the interneuron, held slightly hyperpolarized. $B$, A pulse of depolarizing current in the interneuron reveals its inhibitory effect on a coxal motor neuron. $C$, Moving a spur while the interneuron is at normal membrane potential (arrow 1) evokes a burst of EPSPs in the interneuron and a hyperpolarization in the motor neuron. The same stimulus provided 1 sec later, while the interneuron is momentarily held hyperpolarized by a pulse of DC current (arrow 2), fails to inhibit the motor neuron as much as it did before. Solid bars, duration of the sensory stimuli; stippled lines, onset of the stimulus. Horizontal scale bar: 0.25 sec $(A)$ and 0.5 sec $(B$, $C$ ); vertical scale bar: $8 \mathrm{mV}$. 
DEPRESSOR

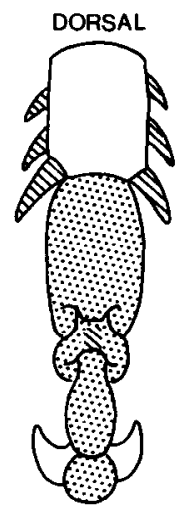

LEVATOR

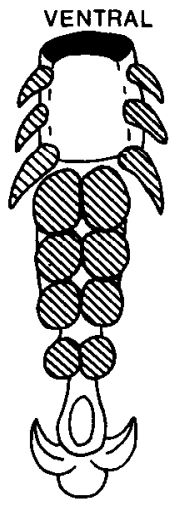

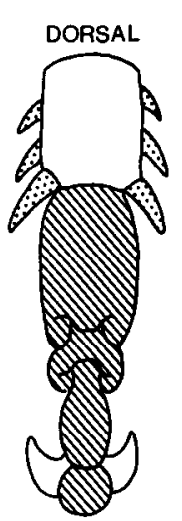

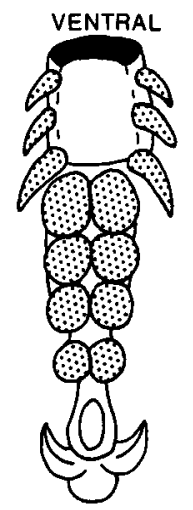

RETRACTOR

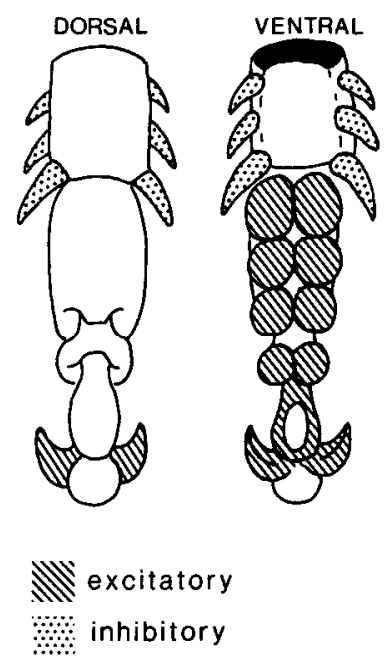

Figure 16. Receptive fields of the 3 pools of tarsal motor neurons. Note that the receptive field of the retractor pool overlaps both with that of the depressor (ventral tarsus) and that of the levator (spurs) pools.

\section{Discussion}

The different pools of tarsal motor neurons can be described by their mechanosensory receptive fields, so that the identity of a motor neuron could, in principle, be determined from a knowledge of its pattern of responses to specific tarsal sensory stimulation (Fig. 16; see below). These receptive fields comprise excitatory and inhibitory regions.

\section{Excitatory regions}

The excitatory regions are first due to direct excitation from the sensory afferents. Short, constant-latency $(1-1.8 \mathrm{msec})$ EPSPs are evoked in specific motor neurons by single identified afferents. The central projections of these afferents and the motor neurons they excite overlap in the neuropil, so that the synaptic contacts are possible. Thus, chordotonal, hair plate, campaniform, canal, and trichoid (hair) afferents can all make direct contacts with leg motor neurons in the locust (or cockroach) (this paper; Pearson et al., 1976; Burrows, 1987a). In the larval Manduca sexta, hairs that mediate a proleg withdrawal reflex connect directly with retractor motor neurons (Weeks and Jacobs, 1987). Our finding of a similar direct effect of hairs on a leg motor neuron in the adult Schistocerca was, however, unexpected, as previous studies pointed towards the prime involvement of local interneurons in the distribution of tactile inputs to the different pools of motor neurons (Siegler and Burrows, 1983, 1986; Laurent and Burrows, 1988). In fact, this idea still prevails, and the hair-motor neuron connection described here appears to be an exception to the rule, for most leg motor neurons so far described do not arborize in the ventral association center, where the hair afferents project (Wilson, 1979; Pflüger et al., 1981; Watson and Burrows, 1982).

\section{Inhibitory regions}

IPSPs evoked in a motor neuron by specific afferents always occur at least 2-3 msec later than EPSPs, indicating a nondirect effect. This delay could be explained by the time needed for a spike to be evoked in one interposed interneuron and its transmitter to be released. The most likely candidates for this inhibitory role are spiking local interneurons. They receive direct inputs from extero- and proprioceptors (Siegler and Burrows,

1983; Burrows, 1987a) and make direct inhibitory connections with certain motor neurons (Burrows and Siegler, 1982) and nonspiking local (Burrows, 1987b; Burrows et al., 1988; Laurent and Burrows, 1988) and intersegmental interneurons (Laurent, 1987b). Some of them show GABA-like immunoreactivity, and their inhibitory action on the motor neurons can be blocked reversibly by picrotoxin, indicating that GABA may be the neurotransmitter involved (Watson and Burrows, 1987). Nonspiking local interneurons, however, also receive direct afferent inputs (Burrows et al., 1988; Laurent and Burrows, 1988) and can make inhibitory connections with motor neurons (Burrows, 1979). The shortest pathway for an afferent to inhibit a motor neuron is therefore through one spiking or nonspiking local interneuron.

\section{Function of polysynaptic pathways}

Indirect pathways through nonspiking local interneurons exist in parallel to the direct sensorimotor connections, as shown, for example, with canal sensilla (Figs. 5 and 14A). These interneurons are affected by the afferents in the same way as the motor neurons they excite (Fig. 17). For example, a nonspiking interneuron exciting the levator motor neuron (levator interneuron) is, like the levator, inhibited by ta2cs (Figs. $11 E$ and $17 B$ ) or spur afferents (Figs. $7 D$ and $17 . A$ ). These polysynaptic pathways provide a substrate for flexibility and central modulation of the reflexes. For example, the stimulation of a spur afferent will give rise to a reflex movement whose amplitude will depend on the state of the interposed interneuron(s) (see Fig. 15). The nonspiking interneurons could therefore, more generally, gate out undesirable reflexes or enhance others at certain phases of the locomotor cycle. Such gain control of sensorimotor pathways has been demonstrated for ocellar inputs in the locust flight control system (Reichert and Rowell, 1985) and for cutaneous inputs in intact, thalamic, or spinal cats walking on a treadmill (Duysens and Pearson, 1976; Forssberg et al., 1977; Forssberg, 1979). The nature and origin of central inputs to nonspiking local interneurons must now be studied in the locust to understand the natural variability in strength (and possibly the phasic gating) of segmental reflexes. 

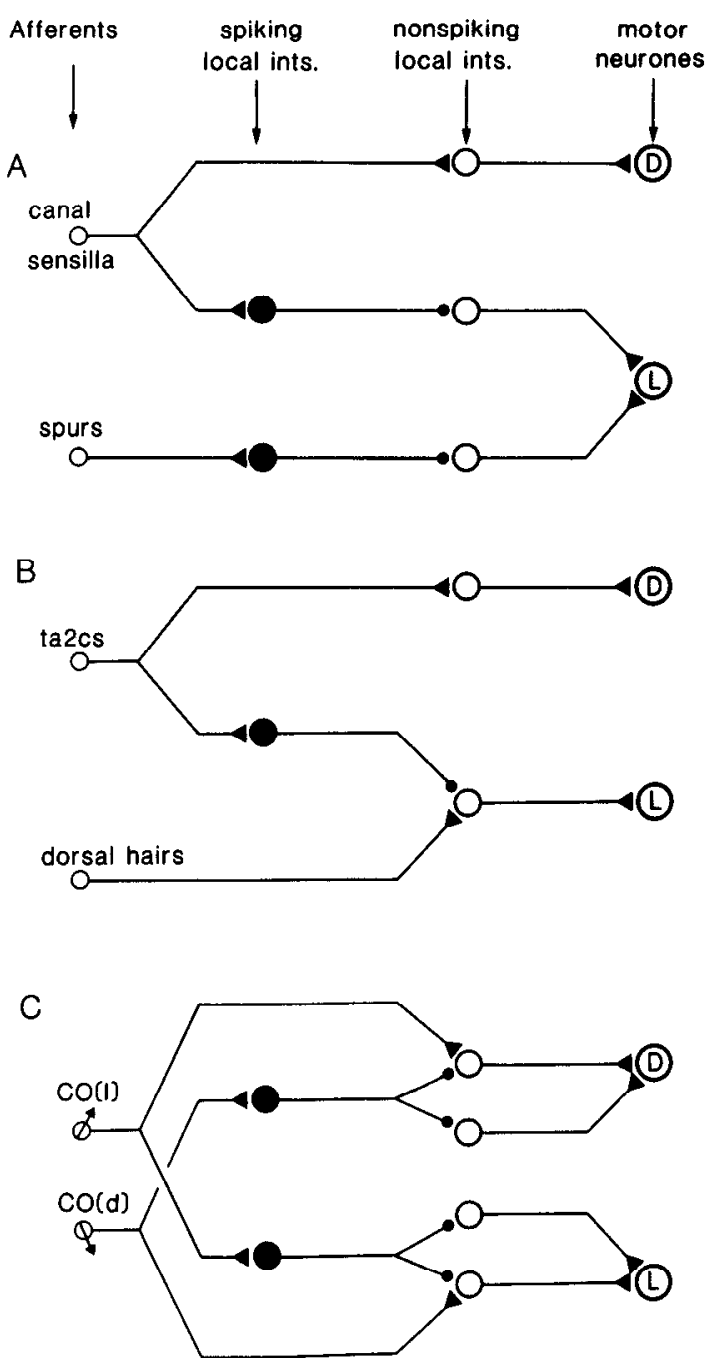

Figure 17. Diagram summarizing the indirect pathways found between the tarsal afferents and motor neurons and involving local interneurons. Triangles, excitatory; circles, inhibitory synapses. The direct connections between afferents and spiking local interneurons are assumed from previous work (Siegler and Burrows, 1983; Burrows and Pfluger, 1986; Burrows, 1987b; Pflüger and Burrows, 1987).

\section{Receptive fields: individual versus pool}

The receptive fields of 2 individuals in a pool of motor neurons are not always identical. For example, 1 or 2 of the 6 retractors are directly excited by the 2 pairs of ungual hairs. Likewise, not all depressors are excited by ta2cs. The receptive field of a motor neuron may therefore be only a fraction of the total receptive field of the pool. We did not, however, find any afferent exciting one member and inhibiting other members of a same motor neuronal pool. This indicates that, while different motor neurons in a pool can be involved in different reflexes, the action of any one does not oppose to the action of the others. Similarly, the receptive field of a nonspiking local interneuron is generally smaller than that of its postsynaptic motor neuron(s): the levator interneuron inhibited by ta 2 cs is unaffected by the spur afferents (Fig. 17B), and the one inhibited by the spur afferents is unaffected by the canal sensilla (Fig. 17A). The control that the nonspiking interneurons exert on the sensorimotor pathways is therefore specific and restricted to the individual.

\section{Variability in synaptic organization?}

The combination of physiological and anatomical criteria used here to describe the motor neurons did not always allow us to identify certain depressors (or retractors) as distinct individuals in their own pool. We thus do not know whether the absence of connection between spur afferents and certain depressor motor neurons is a specific feature of the motor neurons themselves or of the animals in which these experiments were performed. The same conclusion stands for the connections made by canal afferents. These distinctions are particularly important in the light of recent findings (Shepherd and Murphey, 1986; Shepherd et al., 1988) on the cercal sensory system of crickets. These authors studied the probabilistic nature of synaptic connections between hair afferents and giant interneurons and found that, when a connection "exists," it can be described in $50-84 \%$ of normal specimens only. We do not know if similar variations occur in the locust tarsal system. We know, however, that the specific reflexes are always present from animal to animal. We assume, therefore, that if synaptic contacts do vary, a missing connection to one motor neuron must be compensated by another to a different member of its pool.

\section{Functional implications for locomotion}

The receptive fields of the 3 motor pools are shown in Figure 16. The depressors are excited by ventral contact and levitation movements and are inhibited by dorsal contact and depression movements. The receptive field of the levator is the precise mirror image. The retractors have a receptive field that partially overlaps with those of both depressors and levator: excitation by ventral contact is shared with the depressors, inhibition by spur afferents with the levator. Inputs from ventral hairs on the unguis and claw campaniform sensilla (not shown) are unique to the retractors. Understanding the significance of this dual overlap requires considering these various inputs in the context of a step cycle.

Progression of the locust on the complicated terrain of its natural habitat largely depends on the grip established by the tarsi during the stance phase. When the pulvilli first touch the ground, their afferents reflexly excite depressors and retractors and inhibit the levator. The increased depressor activity (supplemented by a resistance reflex excitation from the proprioceptors) first increases the pressure applied by the foot, and, because the pulvilli are soft, this increases the area of contact with the substrate. Second, it increases the thrust applied by the leg to the body. Inhibition of the levator ensures that depressor activity is not opposed. Retractor activation causes the unguis to retract until the claws touch the substrate. The ventrally directed hairs on the unguis and claws then provide further feedback excitation to the retractors. All these sensory afferents can fire tonically for several seconds so that feedback is continually provided. These reflexes thus seem to act synergistically to provide a firm and reliable grip.

At the end of the stance phase, the middle leg will have moved to a retracted position and extend behind its thoracocoxal joint (Burns, 1973). The increase of the tibiotarsal angle will bring the distal anterior spurs in contact with the ground. Their afferents excite the depressors and inhibit the levator and retractors. This could constitute the final preparation for the swing phase. Retraction is brought to an end both by inhibition from the spur afferents and by the decreased pressure on the pulvilli as the ipsilateral legs take the load of the body. As the retractor 
activity decreases, the grip is released, and the leg can move forward. The excitation of the depressors provides the final thrust before the leg is brought forward during the swing phase with the tarsus levated (Fig. $2 A$ ).

The receptive fields of the tarsal motor neurons thus appear to be closely linked with the observed patterns of motor activity (see Fig. 2A). The observation that removing anterior tarsal inputs is accompanied by a decrease in depressor activity during the end of the stance phase (Fig. 2B) supports the assumption that part of the motor activity during walking is shaped by this sensory feedback. We do not imply that tarsal motor neuron activity is solely explained by these mechanosensory receptive fields. What is important, however, is that the receptive fields of these leg motor neurons can be viewed in a functional context appropriate for terrestrial locomotion.

\section{References}

Bacon, J. P., and J. S. Altman (1977) A silver intensification method for cobalt-filled neurones in wholemount preparations. Brain Res. 138: 359-363.

Bekoff, A., M. P. Nusbaum, A. L. Sabichi, and M. Clifford (1987) Neural control of limb coordination. I. Comparison of hatching and walking motor output patterns in normal and deafferented chicks. J. Neurosci. 7: 2320-2330.

Bräunig, P., R. Hustert, and H. J. Pflüger (1981) Distribution and specific central projections of mechanoreceptors in the thorax and proximal leg joints of locusts. I. Morphology, location and innervation of internal proprioceptors of pro- and metathorax and their central projections. Cell Tissue Res. 216: 57-77.

Brogan, R. T., and R. M. Pitman (1981) Axonal regeneration in an identified insect motoneurone. J. Physiol. (Lond.) 319: 34-35P.

Brousse-Gaury, P. (1981) Typologie et topographie des sensilles sur le tarse des mâles de Periplaneta americana L. (Dictyoptères, Blattidés). Ann. Sci. Nat. Zool. (Paris) 3: 69-94.

Burns, M. D. (1973) The control of walking in orthoptera. I. Leg movements in normal walking. J. Exp. Biol. 58: 45-58.

Burrows, M. (1979) Graded synaptic transmission between local premotor interneurons of the locust. J. Neurophysiol. 42: 1108-1123.

Burrows, M. (1980) The control of sets of motoneurones by local interneurones in the locust. J. Physiol. (Lond.) 298: 213-233.

Burrows, M. (1987a) Parallel processing of proprioceptive signals by spiking local interneurones and motor neurones in the locust. J. Neurosci. 7: 1064-1080.

Burrows, M. (1987b) Inhibitory interactions between spiking and nonspiking local interneurones in the locust. J. Neurosci. 7: 3282-3292.

Burrows, M., and H. J. Pflüger (1986) Processing by local interneurones of mechanosensory signals involved in a leg reflex of the locust. J. Neurosci. 6: 2764-2777.

Burrows, M., and M. V. S. Siegler (1982) Spiking local interneurons mediate local reflexes. Science (N.Y.) 217: 650-652.

Burrows, M., and M. V. S. Siegler (1984) The morphological diversity and receptive fields of spiking local interneurones in the locust mctathoracic ganglion. J. Comp. Neurol. 224: 483-508.

Burrows, M., and B. L. Watkins (1986) Spiking local interneurones in the mesothoracic ganglion of the locust: Homologies with metathoracic interneurones. J. Comp. Neurol. 245: 29-40.

Burrows, M., G. J. Laurent, and L. H. Field (1988) Proprioceptive inputs to nonspiking local interneurons contribute to local reflexes of a locust hindleg. J. Neurosci. 8: 3085-3093.

Bush, B. M. H., and M. S. Laverack (1982) Mechanoreception. In The Biology of Crustacea, H. Atwood and D. L. Sandeman, eds., pp. 397467, Academic, New York.

Delcomyn, F. (1980) Neural basis of rhythmic behavior. Science (N.Y.) 210: $492-498$.

Duysens, J., and K. G. Pearson (1976) The role of cutaneous afferents from the distal hindlimb in the regulation of the step cycle of thalamic cats Exp. Brain Res. 24: 245-255.

Egger, D. M., N. C. G. Freeman, M. Jacquin, E. Proshansky, and K. Semba (1986) Dorsal horn cells in the cat responding to stimulation of the plantar cushion. Brain Res. 383: 68-82.
Engberg, I. (1964) Reflexes to foot muscles in the cat. Acta Physiol. Scand. Suppl. 62: 1-64.

Forssberg, H. (1979) Stumbling corrective reaction: A phase-dependent compensatory reaction during locomotion. J. Neurophysiol. 42: 936-953.

Forssberg, H., S. Grillner, and S. Rossignol (1977) Phasic gain control of reflexes from the dorsum of the paw during spinal locomotion. Brain Res. 132: 121-139.

Giuliani, C. A., and J. L. Smith (1987) Stepping behaviors in chronic spinal cats with one hindlimb deafferented. J. Neurosci. 7: 25372546.

Grillner, S. (1985) Neurobiological bases of rhythmic motor acts in vertebrates. Science (N.Y.) 228: 143-149.

Grillner, S., and P. Zangger (1984) The effect of dorsal root transsection on the efferent motor pattern in the cat's hindlimb during locomotion. Acta Physiol. Scand. 120: 393-405.

Hoyle, G., and M. Burrows (1973) Neural mechanisms underlying behavior in the locust Schistocerca gregaria. II. Integrative activity in metathoracic neurons. J. Neurobiol. 4: 42-67.

Hustert, R., H. J. Pflüger, and P. Bräunig (1981) Distribution and specific central projections of mechanoreceptors in the thorax and proximal leg joints of locusts. III. The external mechanoreceptors: The campaniform sensilla. Cell Tissue Res. 216: 97-111.

Jordan, L. (1983) Factors determining motoneurone rhythmicity during fictive locomotion. Symp. Soc. Exp. Biol. 37: 423-444.

Kendall, M. D. (1970) The anatomy of the tarsi of Schistocerca gregaria (Forskal). Z. Zellforsch. 109: 112-137.

Laurent, G. (1987a) Parallel effects of joint receptors on motor neurones and intersegmental interneurones in the locust. J. Comp. Physiol. 160: 341-353.

Laurent, G. (1987b) The role of spiking local interneurones in shaping the receptive fields of intersegmental interneurones in the locust. J. Neurosci. 7: 2977-2989.

Laurent, G. J., and M. Burrows (1988) Direct excitation of nonspiking local interneurones by exteroceptors underlies tactile reflexes in the locust. J. Comp. Physiol. 162: 563-572.

Libersat, F., S. Zill, and F. Clarac (1987) Single-unit responses and reflex effects of force-sensitive mechanoreceptors of the dactyl of the crab. J. Neurophysiol. 57: 1601-1617.

Loeb, G. E. (1985) What the cat's hindlimb tells the cat's spinal cord. In Feedback and Motor Control in Invertebrates and Vertebrates, W. J. P. Barnes and M. H. Gladden, eds., pp. 173-186, Croom Helm, London.

Lynn, B. (1969) The nature and location of certain phasic mechanoreceptors in the cat's foot. J. Physiol. (Lond.) 201: 765-773.

Pearson, K. J., and J. Duysens (1976) Function of segmental reflexes in the control of stepping in cockroaches and cats. In Neural Control of Locomotion. Advances in Behavioral Biology, Vol. 18, R. M. Herman, S. Grillner, P. S. G. Stein, and D. G. Stuart, eds., pp. 519-537, Plenum, New York.

Pearson, K. G., R. K. S. Wong, and C. R. Fourtner (1976) Connexions between hair-plate afferents and motoneurones in the cockroach leg. J. Exp. Biol. 64: 251-266.

Pearson, K. G., D. N. Reye, and R. M. Robertson (1983) Phasedependent influences of wing stretch receptors of flight rhythm in the locust. J. Neurophysiol. 49: 1168-1181.

Pflüger, H. J. (1981) The function of hair sensilla on the locust's leg: The role of tibial hairs. J. Exp. Biol. 87: 163-175.

Pflüger, H. J., and M. Burrows (1987) A strand receptor with a central cell body synapses upon spiking local interneurones in the locust. J. Comp. Physiol. 160: 295-304.

Pflüger, H. J., P. Bräunig, and R. Hustert (1981) Distribution and specific central projections of mechanoreceptors in the thorax and proximal leg joints of locusts. II. The external mechanoreceptors: Hair plates and tactile hairs. Cell Tissue Res. 216: 79-96.

Pitman, R. M., C. D. Tweedle, and M. J. Cohen (1972) Branching of central neurons: Intracellular cobalt injection for light and electron microscopy. Science (N.Y.) 176: 412-414.

Reichert, H., and C. H. F. Rowell (1985) Integration of nonphaselocked exteroceptive information in the control of rhythmic flight in the locust. J. Neurophysiol. 53: 1201-1218.

Reichert, H., M. R. Plummer, and J. J. Wine (1983) Identified nonspiking local interneurones mediate nonrecurrent, lateral inhibition of crayfish mechanosensory interneurones. J. Comp. Physiol. 151. 261-276. 
Reye, D. N., and K. G. Pearson (1987) Projections of the wing stretch receptors to central flight neurons in the locust. J. Neurosci. 7: 24762487.

Reye, D. N., and K. G. Pearson (1988) Entrainment of the locust central flight oscillator by wing stretch receptor stimulation. J. Comp. Physiol. 162: 77-89.

Shepherd, D., and R. K. Murphey (1986) Competition regulates the efficacy of an identified synapse in crickets. J. Neurosci. 6: 31523160.

Shepherd, D., G. Kamper, and R. K. Murphey (1988) The synaptic origins of receptive field properties in the cricket cercal sensory system. J. Comp. Physiol. 162: 1-11.

Siegler, M. V. S., and M. Burrows (1983) Spiking local interneurons as primary integrators of mechanosensory information in the locust. J. Neurophysiol. 50: 1281-1295.

Siegler, M. V. S., and M. Burrows (1986) Receptive fields of motor neurones underlying local tactile reflexes in the locust. J. Neurosci. 6: $507-513$.

Stevenson, P. A., and W. Kutsch (1987) A reconsideration of the central pattern generator concept for locust flight. J. Comp. Physiol. 161: 115-129.

Stilwell, D. L. (1957) The innervation of deep structures of the foot. Am. J. Anat. 101: 59-73.

Tyrer, N. M., and G. E. Gregory (1982) A guide to the neuroanatomy of locust suboesophageal and thoracic ganglia. Phil. Trans. R. Soc. London [Biol.] 297: 91-123.

Usherwood, P. N. R., H. I. Runion, and J. I. Campbell (1968) Structure and physiology of a chordotonal organ in the locust leg. J. Exp. Biol. 48: 305-323.

von Holst, E. (1935) Erregungsbildung und Erregungs leitung im Fischruckenmark. Pfluegers Arch. Ges. Physiol. 235: 345-359.
Watson, A. H. D., and M. Burrows (1982) The ultrastructure of identified locust motor neurones and their synaptic relationships. J. Comp. Neurol. 205: 383-397.

Watson, A. H. D., and M. Burrows (1987) Immunocytochemical and pharmacological evidence for GABAergic spiking local interneurones in the locust. J. Neurosci. 7: 1741-1751.

Wecks, J. C., and G. A. Jacobs (1987) A reflex behavior mediated by monosynaptic connections between hair afferents and motoneurons in the larval tobacco hornworm. J. Comp. Physiol. 160: 315-329.

Wilson, D. M. (1961) The central nervous control of flight in a locust. J. Exp. Biol. 38: 471-490.

Wilson, J. A. (1979) The structure and function of serially homologous leg motor neurons in the locust. I. Anatomy J. Neurobiol. 10:41-65.

Woolf, C. J., and M. Fitzgerald (1983) The properties of neurones recorded in the superficial dorsal horn of the rat spinal cord. J. Comp. Neurol. 221: 313-328.

Woolf, C. J., and M. Fitzgerald (1986) Somatotopic organisation of cutaneous afferent terminals and dorsal horn neuronal receptive fields in the superficial and deep laminae of the rat lumbar spinal cord. J. Comp. Neurol. 251: 517-531.

Woolf, C. J., and A. E. King (1987) Physiology and morphology of multireceptive neurons with C-afferent fiber inputs in the deep dorsal horn of the rat lumbar spinal cord. J. Neurophysiol. 58: 460-479.

Young, D. (1970) The structure and function of a connective chordotonal organ in the cockroach leg. Phil. Trans. R. Soc. London [Biol.] 256: $401-428$.

Zill, S. N. (1985) Proprioceptive feedback and the control of cockroach walking. In Feedback and Motor Control in Invertebrates and Vertebrates, W. J. P. Barnes and M. H. Gladden, eds., pp. 187-208, Croom Helm, London. 